\title{
Synthetic Biology Tools for Novel Secondary Metabolite Discovery in Streptomyces
}

\author{
Namil Lee ${ }^{1}$, Soonkyu Hwang ${ }^{1}$, Yongjae Lee ${ }^{1}$, Suhyung Cho ${ }^{1}$, Bernhard Palsson ${ }^{3,4,5}$, and Byung-Kwan Cho ${ }^{1,2 *}$ \\ ${ }^{1}$ Department of Biological Sciences and KI for the BioCentury, Korea Advanced Institute of Science and Technology, Daejeon 34141, Republic \\ of Korea \\ ${ }^{2}$ Intelligent Synthetic Biology Center, Daejeon 34141, Republic of Korea \\ ${ }^{3}$ Department of Bioengineering, University of California San Diego, La Jolla, CA, 92093, USA \\ ${ }^{4}$ Department of Pediatrics, University of California San Diego, La Jolla, CA, 92093, USA \\ ${ }^{5}$ Novo Nordisk Foundation Center for Biosustainability, Technical University of Denmark, Lyngby, 2800, Denmark
}

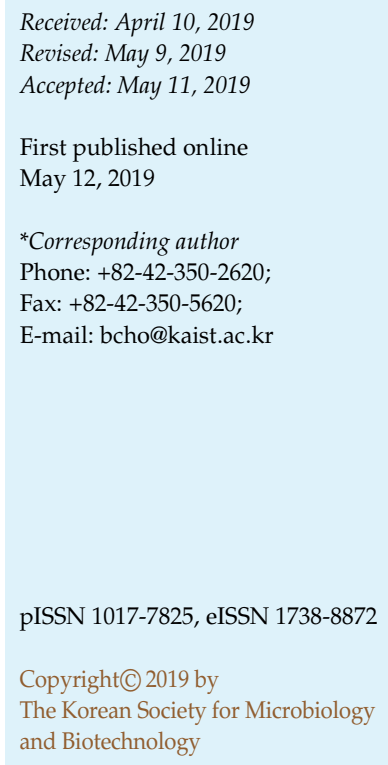

Streptomyces are attractive microbial cell factories that have industrial capability to produce a wide array of bioactive secondary metabolites. However, the genetic potential of the Streptomyces species has not been fully utilized because most of their secondary metabolite biosynthetic gene clusters (SM-BGCs) are silent under laboratory culture conditions. In an effort to activate SM-BGCs encoded in Streptomyces genomes, synthetic biology has emerged as a robust strategy to understand, design, and engineer the biosynthetic capability of Streptomyces secondary metabolites. In this regard, diverse synthetic biology tools have been developed for Streptomyces species with technical advances in DNA synthesis, sequencing, and editing. Here, we review recent progress in the development of synthetic biology tools for the production of novel secondary metabolites in Streptomyces, including genomic elements and genome engineering tools for Streptomyces, the heterologous gene expression strategy of designed biosynthetic gene clusters in the Streptomyces chassis strain, and future directions to expand diversity of novel secondary metabolites.

Keywords: Streptomyces, secondary metabolites, biosynthetic gene cluster, antibiotics, synthetic biology, genome editing, CRISPR/Cas9, heterologous expression

\section{Introduction}

Streptomyces species are Gram-positive bacteria that produce more than two-thirds of the medically and agriculturally important secondary metabolites, including antibiotic, anticancer, antifungal, antiparasitic, and immunosuppressive compounds [1, 2]. Recent genome sequencing efforts have revealed that individual Streptomyces species have a wealth of genetic potential to produce novel secondary metabolites. However, most secondary metabolite biosynthetic gene clusters (SM-BGCs) are silent under laboratory culture conditions, limiting effective use of Streptomyces [3]. Therefore, activation of silent SM-BGCs is one of the most promising approaches to discover novel bioactive secondary metabolites from Streptomyces.
To activate silent SM-BGCs, various strategies have been applied, including culture media modifications, chemical or antibiotic treatments, heterologous gene expression in different hosts, and co-culture with cohabiting microbes [4]. However, these methods are untargeted, resulting in non-directed activation of silent SM-BGCs in Streptomyces. To overcome this limitation, a synthetic biology approach has been proposed to redesign and reconstruct target SMBGCs $[5,6]$. Generally, a main obstacle in activating cryptic SM-BGCs is the difficulty in bypassing the complex native regulation. Expression of SM-BGCs is tightly governed by multi-layered regulatory networks, which are often triggered by environmental signals [7]. Using synthetic genetic parts, such as promoters, ribosome binding sites (RBS), and terminators, which are not controlled by the 

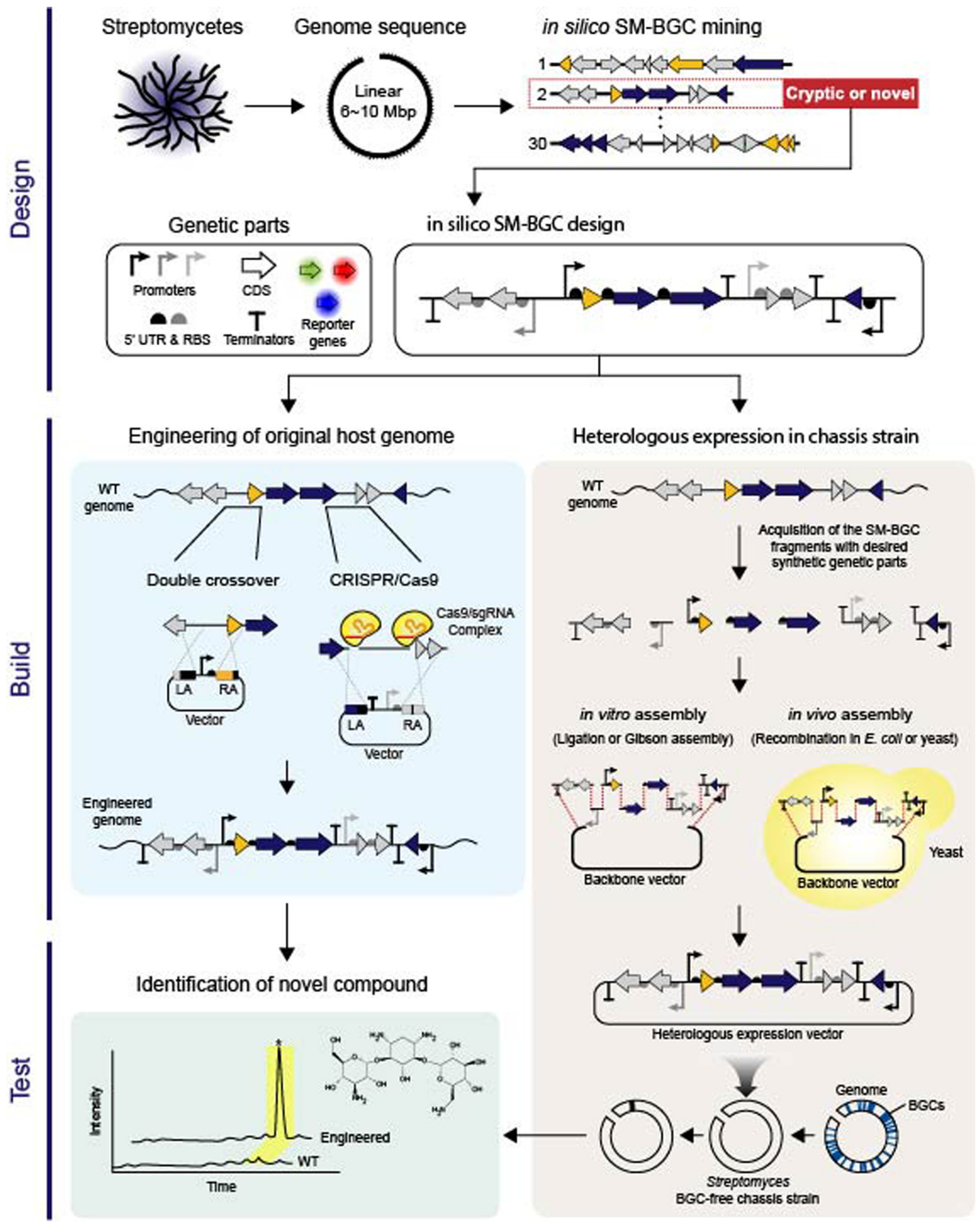

Fig. 1. Overview of synthetic biology strategy to produce novel secondary metabolite from Streptomyces.

Abbreviations: BGC, biosynthetic gene cluster; CDS, coding sequence; $5^{\prime}$ UTR, $5^{\prime}$ untranslated region; RBS, ribosome binding site; WT, wild type; LA, left homology arm; RA, right homology arm.

host's regulatory system, expression of target SM-BGC can be achieved through bypassing the native regulatory networks. In this respect, various synthetic genetic parts and genome engineering tools are required to regulate gene expression and redesign target SM-BGCs in Streptomyces. Even though high GC content and highly interconnected regulatory networks challenge the application of synthetic genetic parts that are widely used in other bacterial 
systems to Streptomyces, enabling synthetic biology tools have been recently developed for Streptomyces engineering [8]. Here, we review synthetic biology strategies applied in the discovery of novel secondary metabolites in Streptomyces. As synthetic biology is defined by an iterative "designbuild-test" cycle in engineering biology, we have classified the strategy into three steps (Fig. 1). First, for the design step, discovery of novel SM-BGCs via genome mining is described, followed by designing of SM-BGCs using various synthetic genetic parts developed for Streptomyces. Second, for the build step, the process of building the redesigned SM-BGCs is discussed, including genome engineering of original host and SM-BGC assembly into plasmids for heterologous expression. Further, Streptomyces chassis strains are suggested as optimal heterologous expression hosts for reconstructing target SM-BGCs. Third, for the test step, high-throughput testing methods are described to measure activation of target SM-BGCs for the next "design-build-test" cycle.

\section{Mining of Secondary Metabolite Biosynthetic Gene Clusters}

In the pre-genome mining era, most of the secondary metabolites in Streptomyces were discovered via chemistrybased methods of changing culture conditions and mass spectrometry or NMR biosynthetic identification [9]. Due to the biochemical complexity of SM-BGCs, however, the discovery of novel secondary metabolites has been challenging. This limitation has been overcome through a genome mining approach, in which recent advances in DNA sequencing technology caused a rapid increase in the number of high-quality Streptomyces genome sequences $[10,11]$. To date, about 500 scaffold-level and 84 completelevel genome sequences of Streptomyces strains are available in the NCBI database. These large numbers of genome sequences encode invaluable resources for novel secondary metabolite discovery [12]. To identify SM-BGCs from these genome sequences, several genome-mining tools have been developed, such as ClustSCAN, NP.searcher, GNP/PRISM, and antiSMASH [13-16]. Among them, antiSMASH is the most comprehensive and widely used software pipeline for genome mining, offering a userfriendly web interface and prediction of the broad spectrum of SM-BGCs [16]. antiSMASH has detected 45 different classes of SM-BGCs based on a rule-based cluster detection approach and further predicted the modular domain structures of genes within these SM-BGCs [17].

In general, each Streptomyces genome encodes approxi- mately 30 SM-BGCs, which are diverse and differ between species, indicating that Streptomyces strains are an immeasurable source of novel secondary metabolites [1820]. Information about SM-BGCs mined from genome sequences is not only essential data for novel secondary metabolite discovery, but also a resource to facilitate rational design of SM-BGCs based on the synthetic biology approach. In particular, polyketides (PK) and nonribosomal peptides (NRP) can be redesigned using this approach as they are synthesized by serially connected modular enzymes that recognize module-specific CoAs or amino acids, respectively [21]. For example, replacement of AveA1 and module 7 of AveA3 in avermectin BGC of Streptomyces avermitilis with MilA1 and MilA3 in milbemycin BGC of $S$. hygroscopicus resulted in milbemycin production in S. avermitilis [22]. Taken together, a genome mining approach can accelerate secondary metabolite discovery at an unprecedented rate with an ever-growing number of Streptomyces genome sequences.

\section{Genetic Parts for Streptomyces Synthetic Biology}

Genomic information on Streptomyces strains has revealed the great potential of Streptomyces to produce novel secondary metabolites. However, most SM-BGCs in Streptomyces are inactive under general laboratory culture conditions. For example, although S. coelicolor, S. griseus, and $S$. avermitilis genomes encode more than 30 SM-BGCs, respectively, only 3-5 secondary metabolites have been detected [1, 11,23]. Although many efforts have been made to activate silent SM-BGCs in Streptomyces strains, including the One Strain-Many Compounds (OSMAC) strategy and co-cultivation methods [24, 25], these approaches resulted in non-directed activation of silent BGCs. For specific activation of targeted SM-BGCs, the following methods have been implemented: (1) promoter replacement, (2) overexpression or repression of regulatory genes, (3) heterologous expression in different hosts, and (4) refactoring of targeted SM-BGCs [26]. To this end, the number of genetic parts, such as promoters, ribosomebinding sites (RBS), and terminators available for Streptomyces species, has dramatically increased as summarized in Table 1.

\section{Genetic Parts for Transcriptional Regulation in Streptomyces}

In bacterial cells, a transcription unit is defined as a basic unit of regulation and is composed of several genes and accessory genetic elements, including promoters, transcription start sites (TSS), RBSs, and terminators. Design and 
Table 1. Genetic parts for Streptomyces.

\begin{tabular}{|c|c|c|}
\hline Genetic parts & Feature & Reference \\
\hline \multicolumn{3}{|l|}{ Constitutive promoters } \\
\hline ermE* promoter & Mutation at the promoter of the erythromycin resistance gene of Streptomyces erythraeus & [31] \\
\hline SF14P promoter & Genome of Streptomyces ghanaensis phage I19 & [34] \\
\hline kasOP promoter & Promoter of SARP family regulator in Stretpomyces coelicolor A3 & [33] \\
\hline gapdh promoter & Promoter of glyceraldehyde-3-phosphate dehydrogenase in Streptomyces griseus & [35] \\
\hline rpsL promoter & Promoter of 30 S ribosomal protein S12 in Streptomyces griseus & [35] \\
\hline 195 native or synthetic promoters & High-throughput screening in S. venezueale & [58] \\
\hline 32 native promoters & Transcriptome data-based selection in S. albus & [38] \\
\hline 166 native promoters & Transcriptome data-based selection in S. coelicolor & [39] \\
\hline 2 native promoters & Multi-omics data-based selection in S. coelicolor & [59] \\
\hline \multicolumn{3}{|l|}{ Inducible promoters } \\
\hline tipA promoter & Thiostrepton-induced promoter & [40] \\
\hline nit $A$ promoter & $\varepsilon$-caprolactam-induced promoter & [45] \\
\hline xylA promoter & Xylose-induced promoter & [46] \\
\hline tcp830 & Tetracycline-induced promoter & [43] \\
\hline PA3-rolO & Resorcinol-induced promoter & [44] \\
\hline P21-cmt & Cumate-induced promoter & [44] \\
\hline \multicolumn{3}{|l|}{ Terminators } \\
\hline $\mathrm{Fd}$ & Bidirectional transcription termination originated from E. coli phage $\mathrm{fd}$ & [48] \\
\hline TD1 & Bidirectional transcription termination originated from Bacillus subtilis phage $Ф 29$ & [49] \\
\hline \multicolumn{3}{|l|}{ RBS } \\
\hline AAAGGAGG & Typical RBS sequence of S. coelicolor & [134] \\
\hline 192 native or synthetic RBSs & High-throughput screening in S. venezueale & [58] \\
\hline 4 native RBSs & Multi-omics data-based selection in S. coelicolor & [59] \\
\hline \multicolumn{3}{|l|}{ Reporter genes } \\
\hline lux $A B$ cassette & $\mathrm{n}$-Decanal as substrate; absorbance at $490 \mathrm{~nm}$ wavelength & [61] \\
\hline amy gene & Soluble starch with 3,5-dinitrosalycilic acid (DNS) as substrate; absorbance at $540 \mathrm{~nm}$ wavelength & [64] \\
\hline xylE gene & Catecol as substrate; absorbance at $375 \mathrm{~nm}$ wavelength & [62] \\
\hline gus $A$ gene & p-Nitrophenyl- $\beta$-D-glucuronide as substrate; absorbance at $415 \mathrm{~nm}$ wavelength & [63] \\
\hline eGFP & Green fluorescent protein; excitation wavelength $470-490 \mathrm{~nm}$ and emission wavelength $515 \mathrm{~nm}$ & [65] \\
\hline sfGFP & Green fluorescent protein; excitation wavelength $488 \mathrm{~nm}$ and emission wavelength 500 550 nm & [58] \\
\hline mRFP & Red fluorescent protein; excitation wavelength $584 \mathrm{~nm}$ and emission wavelength $607 \mathrm{~nm}$ & [67] \\
\hline mCherry & Red fluorescent protein; excitation wavelength $587 \mathrm{~nm}$ and emission wavelength $610 \mathrm{~nm}$ & [68] \\
\hline
\end{tabular}

utilization of these genetic parts, at appropriate strengths, is critical for precise transcriptional and translational regulation of targeted gene expression. In transcriptional regulation, the most important genetic part is the promoter, which is the binding site of RNA polymerase to initiate transcription. However, widely used promoters for bacterial genetic engineering, such as lacZ and T7 promoters, are not directly applicable in Streptomyces [27, 28], thus only a few promoters have been used for gene expression in Streptomyces. The terminator is also important in preventing transcriptional read-through to downstream genes [29]. Particularly, when redesigning SM-BGCs in Streptomyces, due to their operonlike genomic structure, precise transcriptional termination is required between transcription units. In this section, we described genetic parts that have been developed and used to regulate the transcription of Streptomyces.

First, constitutive promoters, which generate constant gene expression levels regardless of growth phases, are extensively used for SM-BGC expression in Streptomyces. In particular, ermE* promoter is the most commonly used 
strong constitutive promoter in Streptomyces, which is a derivative of the ermE promoter, containing a trinucleotide deletion in the ermEp1 region of the erythromycin resistance gene in S. erythraeus [30-32]. Further, SF14P and $k a s O P$, discovered from the $S$. ghanaensis phage I19 genome and promoter of the SARP family regulator in $S$. coelicolor A3, respectively, constitutively transcribe gene expression similarly or more strongly than the ermE* promoter [33, 34]. Additionally, two strong constitutive promoters, gapdhP and $\operatorname{rps} L P$, which have higher activity than the ermE* promoter, were obtained from the promoter region of housekeeping genes in the $S$. griseus genome [35]. In addition, several strategies have been applied to develop strong constitutive promoters. One approach screens strong synthetic promoters from a randomized promoter library. For example, the randomized sequence library of the $k a s O$ promoter was used to generate synthetic promoters with promoter strength ranging from $0.95 \%$ to $187.5 \%$, compared to the parental $k a s O$ promoter [33]. Similar approaches have been conducted on the ermE and actII-orf4 promoters of S. coelicolor [36]. Several strong promoters were screened through this approach; however, all promoters were weaker than the ermE* promoter [37]. Another rational strategy identifies strong promoters using gene expression data. In $S$. albus, promoter sequences of highly expressed genes were selected based on transcriptional profiling data, and the strength of each promoter was tested, resulting in the selection of ten promoters that were stronger than the ermE* promoter [38]. A similar study was performed on S. coelicolor, which identified 166 potentially constitutive promoters across the Streptomyces genus [39].

Second, expression of SM-BGC genes under constitutive promoters sometimes causes growth retardation. Therefore, it is desirable to establish a controllable gene expression system in Streptomyces. To date, the most widely used inducible promoter in Streptomyces is the tipA promoter, which is induced by thiostrepton treatment $[40,41]$. The basal expression level of the tipA promoter is considerable, which limits precise regulation of the targeted gene expression. However, basal expression of the tipA promoter is sometimes used to maintain low expression levels of toxic genes [42]. The tetracycline-induced strong promoter, tcp830, was constructed by combining conserved sequences of the ermE promoter and Tn10 tetR/tetO systems [43]. However, like tipA promoter, a major disadvantage of this promoter is its basal expression level. To overcome this limitation, inducible promoters with low leaky expression, such as PA3-rolO and P21-cmt promoters, have been synthesized. The PA3-rolO promoter is a resorcinol-induced promoter synthesized by combining the rolO operator and synthetic promoter $P A 3$. The $P 21$-cmt promoter is a cumateinduced expression system synthesized by fusing the operator of the Pseudomonas putida F1 cumate degradation operon to the P21 synthetic promoter [44]. Other inducible systems used in Streptomyces are nit A and xylA promoters. The nit $A$ promoter, which originates from the nitrilase promoter of Rhodococcus rhodochrous, is induced by a complex of $\varepsilon$-caprolactam and the transcription regulator NitR [45]. The recently developed $x y l A$ promoter is a strictly regulated xylose-induced expression promoter [46]. Additionally, several glycerol-inducible systems have been developed for Streptomyces; however, these systems have not been utilized because glycerol treatment may alter intrinsic cellular metabolism [47].

Further, only a limited number of terminator sequences is available in Streptomyces strains. Two bidirectional transcription terminators, Fd originated from Escherichia coli phage fd and TD1 originated from Bacillus subtilis phage $\varphi 29$, are efficiently recognized in Streptomyces [48, 49]. Although lambda T0 and T7 terminators have been used in several Streptomyces vectors, these terminators have not been systematically validated in Streptomyces for their effects on gene expression levels [50]. While most studies have focused on promoter strength as a determinant of gene expression levels, transcription terminators also have crucial roles in recycling transcription complexes and ultimately gene expression level [51, 52]. To expand the repertoire of transcription terminators in Streptomyces, understanding transcription termination and identifying native terminator sequences in Streptomyces are required. In this regard, Term-seq, which is a recent RNA sequencing method that enables genome-wide determination of transcript $3^{\prime}$ end positions, is a suitable technique for screening terminator sequences in Streptomyces genomes [53].

Taken together, many efforts in molecular biology of Streptomyces have provided genetic parts to control gene expression, including constitutive promoters, inducible promoters, and terminators. However, to flexibly and precisely control secondary metabolite production in Streptomyces, more generalized and validated genetic parts for transcription, which can be used in various Streptomyces species and at different strengths, have to be developed.

\section{Genetic Parts for Translational Regulation in Streptomyces}

Because cellular protein level does not directly correlate with mRNA abundance, yet depends on translational 
efficiency, transcriptional regulation alone is not sufficient to design an efficient gene expression system in Streptomyces $[54,55]$. Translational efficiency is primarily determined by $5^{\prime}$ untranslated regions (5'-UTR), RBS, and codon usage of target genes [56]. For example, the RBS contains the Shine Dalgarno (SD) sequence, which includes a complementary sequence with the $3^{\prime}$ end of the 16s rRNA region of the 30S ribosomal subunit. Sequence diversity and accessibility of the SD sequence influence binding affinity with the ribosome, determining translational efficiency [57]. In this regard, several studies have measured the strength of the $5^{\prime}$-UTR and RBS in Streptomyces species to expand genetic parts for Streptomyces engineering. In this section, we will provide two examples of translational regulatory genetic part screenings in Streptomyces genomes.

First, in S. venezuelae, sequences of the strongest RBS among 15 native RBSs were selected and randomized. After comparing the RBS strength, 177 synthetic RBSs with activity over 200-fold compared to their parental RBSs were collected. Furthermore, seven promoters were combined with nine RBSs in a pairwise manner to screen the most optimal promoter-RBS set for gene expression [58]. Second, two promoters and four $5^{\prime}$-UTR sequences were selected from S. coelicolor based on multi-omics data, including TSSseq, RNA-seq, and Ribo-seq. Pairwise sets of promoters and 5'-UTR sequences showed strength in a range of 0.03to 2.4-fold, compared to the $\mathrm{rrmE}^{*}$ promoter with the SD sequence of the nit $A$ gene [59]. Although development of a translational regulatory genetic part is at the beginning stage, as compared to transcription, ultimately transcriptional and translational genetic parts with various strengths have to be combined and utilized to design and control enzyme stoichiometry in SM-BGCs for enhancing secondary metabolite production.

\section{Reporter Systems for High-Throughput Screening}

For high-throughput characterization of genetic parts developed for Streptomyces, reporter systems that rapidly represent gene expression level with minimal influence to the cell physiology are required. Although many antibiotic resistance genes have been used as conventional markers for gene expression, their effects on cellular metabolism and narrow dynamic range limit their suitability for gene expression quantification [32,60]. To quantify gene expression, colorimetric methods are more appropriate because gene expression levels can be quantified by measuring the absorbance of a specific wavelength of light. To date, various colorimetric methods, including $\operatorname{lu} x A B$, $a m y, x y l E$, and gus $A$, have been employed in Streptomyces strains [61-64]. In particular, gusA is the most widely used colorimetric reporter system in Streptomyces strains [44, 59]. However, colorimetric reporter systems are based on an enzymatic reaction that requires an additional substrate treatment, which may affect cellular metabolism (Table 1). For example, catechol dioxygenase, encoded by $x y l E$, produces hydroxymuconic semialdehyde with a yellow color from catechol as a substrate [62]. In contrast, fluorescent proteins do not require any supplemental reagents and thus are suitable for high-throughput screening using fluorescence-activated cell sorting (FACS). However, since Streptomyces have relatively high levels of autofluorescence, several studies have argued that fluorescent proteins are not appropriate for high-throughput screening of Streptomyces strains [63]. Despite this limitation, several efforts have been made to apply fluorescent proteins in Streptomyces [65]. Among the fluorescent proteins, GFP derivatives, such as eGFP and sfGFP, are widely used in Streptomyces, and mRFP has been implemented to enable multi-color fluorescence-based studies [58, 65-67]. To test the available fluorescent proteins in $S$. venezuelae, seven fluorescent proteins (mTagBFP, mCerulean, mTFP, sfGFP, mCherry, mKate, and mCardinal) were expressed, and the fluorescence intensity of each fluorescent protein was compared. Among the seven fluorescent proteins, mCherry protein showed the most significant reduction in signal-to-background noise level and was used for further studies to characterize genetic parts of S. venezuelae [68].

\section{CRISPR/Cas-Based Genome-Engineering Tools for Streptomyces}

To utilize genetic parts and reconstruct metabolic pathways for secondary metabolite production, efficient genome engineering tools are required. Conventional genome engineering of Streptomyces is heavily dependent on either single or double crossover of a plasmid, which is laborious and time-consuming to obtain the desired clones [32]. Furthermor, the use of selection markers, such as antibiotics resistance genes, is often required to avoid reversion of the engineered genotype to wild type and may confer undesired effects, including polar effects. To overcome this limitation, site-specific recombination strategies, including Cre/loxP, Dre/rox and Flp/FRT, have been exploited in Streptomyces [69-72]. However, these approaches retain recombinase recognition sites in the chromosome and may limit successive applications for multiple genetic manipulations.

Recently, CRISPR/Cas9 (clustered regularly interspaced 
short palindromic repeats and CRISPR-associated protein 9) has emerged as a promising tool for genome engineering of Streptomyces strains [50,73-78]. Briefly, the Cas9 endonuclease forms a complex with guide RNA (gRNA) and is guided to a protospacer sequence, which is complementary to a spacer sequence of gRNA [79]. The guided Cas9 induces a double-strand break (DSB) in the genome, followed by repairing the DSB via native non-homologous end joining repair (NHEJ) or homology directed repair (HDR) mechanisms which facilitate genome engineering. CRISPR/Cas9 systems are superior to simple homologous recombination or site-specific recombination systems as they facilitate unmarked genome engineering with reduced time and labor. Even though other genome engineering strategies, such as zinc finger nuclease and transcription activator-like effector nuclease, have been developed, the proteinmediated recognition of target DNA sequence requires design of appropriate proteins for individual target sequences and thus limits their applications [80-82]. Therefore, the CRISPR/ Cas9 system has become a dominant genome engineering tool, outpacing their performance (Table 2) [83].

\section{Editing Streptomyces Genomes and Secondary Metabolite Biosynthetic Gene Clusters}

The DSB by Cas9 occurs only if a specific sequence motif, called a protospacer adjacent motif (PAM), is present next to the protospacer [84]. All applications of the CRISPR/ Cas9 system in Streptomyces strains utilize Cas9 from Streptococcus pyogenes (SpCas9), whose cognate PAM sequence is 5'-NGG [85]. As a large portion of Streptomyces genome is typically composed of G and C, SpCas9 offers plenty of potential target sites for CRISPR/Cas9-based genome engineering. Using the CRISPR/Cas9 system, genetic manipulations, including deletion, insertion, and point mutation, have been executed in various Streptomyces species $[18,42,50,86-94]$.

CRISPR/Cas9-based approaches can be divided by the type of DSB repair, NHEJ and HDR. NHEJ-mediated genome engineering generates random mutation, insertion or deletion of a few nucleotides, to disrupt a gene of interest $[86,88,93]$. Further, it has been applied to S. coelicolor and S. rimosus to disrupt actinorhodin synthesis and the pentose phosphate pathway, respectively. However, this technology was inefficient since the NHEJ system of most Streptomyces species is incomplete [86]. To enhance NHEJbased genome engineering efficiency, LigD, the lacking component of NHEJ, was simultaneously introduced into S. coelicolor with CRISPR/Cas9 [86]. However, to avoid this limitation, CRISPR/Cas9-mediated genome engineering approaches in Streptomyces utilize HDR. For HDR-mediated genome engineering, template DNA for homologous recombination is introduced with CRISPR/Cas9 to enhance production of secondary metabolites and activate cryptic SM-BGCs in Streptomyces [87, 89, 90,93]. For example, oxytetracycline production was increased in S. rimosus by deleting $z w f 2$ and $\operatorname{dev} B$, and redirecting oxygen and NADPH to oxytetracycline biosynthesis [93]. In addition, knock-in of a strong promoter upstream of pathwayspecific transcriptional activators or secondary metabolite biosynthesis genes increased secondary metabolite production and activated silent SM-BGCs [87].

In addition to the in vivo genome engineering, CRISPR/ Cas9 can be utilized for cloning and refactoring of large SM-BGCs [89, 95-99]. Restriction enzymes or PCR-based cloning strategies are not suitable for manipulation of large-sized DNA fragments due to the limited restriction sites and DNA amplification errors. The high-resolution site-specific cleavage activity of the CRISPR/Cas9 system enables efficient in vitro manipulation of large SM-BGCs, up to $100 \mathrm{~kb}$ [96]. In addition, multiplexed refactoring of promoters in a SM-BGC has been facilitated by using a CRISPR/Cas9 system with transformation-associated recombination (TAR) in yeast [97]. Therefore, these in vitro SMBGC engineering tools will provide an efficient strategy for cloning and repurposing SM-BGCs to enhance secondary metabolite production and activate silent SM-BGCs.

\section{CRISPR/Cas9-Based Transcriptional Repression and Activation}

Cas9 contains two nuclease domains, RuvC1 and $\mathrm{HNH}$, which are responsible for DSB formation at the target DNA sequence [79]. Introduction of two silencing mutations to the RuvC1 and HNH nuclease domains (D10A and H840A) generates catalytically dead Cas9 (dCas9), which lacks nuclease activity yet retains DNA binding activity. By guiding dCas9 to the promoter region or coding region of the target gene, transcription initiation or transcription elongation can be blocked, respectively [100]. The CRISPR/ dCas9-based transcriptional repression system, called CRISPR interference (CRISPRi), has been exploited for transcriptional repression of genes in S. coelicolor [86, 101]. Further, transcriptional repression of genes within SMBGC by the CRISPRi resulted in decreased production of secondary metabolites [86, 101]. In addition, transcriptional repression by CRISPRi system can be utilized to screen functional genes [101]. Although a high-throughput functional gene screening system based on transposon sequencing (Tn-seq) has been implemented in Streptomyces, the 
Table 2. Application of CRISPR/Cas9-mediated engineering in Streptomyces.

\begin{tabular}{|c|c|c|c|c|c|c|c|c|}
\hline Cas & Target & Strategy & Vector & Repair & Organism & $\begin{array}{l}\text { Related secondary } \\
\text { metabolite }\end{array}$ & Remark & Ref \\
\hline \multirow[t]{19}{*}{ SpCas9 } & actI-orf1 & Disruption & pCRISPR-Cas9 & NHEJ & S. coelicolor & ACT & $\begin{array}{l}\text { Reconstituted NHEJ with } \\
\text { ligD expression }\end{array}$ & [86] \\
\hline & actVB & Disruption & pCRISPR-Cas9 & NHEJ & S. coelicolor & $\mathrm{ACT}$ & $\begin{array}{l}\text { Reconstituted NHEJ with } \\
\text { ligD expression }\end{array}$ & \\
\hline & actI-orf2 & Disruption & pWHU & NHEJ & S. coelicolor & ACT & $\begin{array}{l}\text { codA(sm)-based } \\
\text { screening system for } \\
\text { plasmid-cured strain }\end{array}$ & [88] \\
\hline & zwf2 & Disruption & pCRISPomyces & NHEJ & S. rimosus & - & $\begin{array}{l}\text { Oxytetracycline } \\
\text { production enhancement } \\
\text { by disruption of } \\
\text { competitive gene }\end{array}$ & [93] \\
\hline & sshg_00040 - sshg_00050 & Deletion & pCRISPomyces & HDR & S. albus & Lanthipeptide & - & [50] \\
\hline & sshg_05713 & Deletion & pCRISPomyces & HDR & S. albus & $\begin{array}{l}\text { Polycylic tetramic } \\
\text { acid macrolactam }\end{array}$ & - & \\
\hline & Formicamycin cluster & Deletion & pCRISPomyces & HDR & S. formicae & Formicamycin & - & [91] \\
\hline & forV & Deletion & pCRISPomyces & HDR & S. formicae & Formicamycin & - & \\
\hline & actVA-orf5 & Deletion & pCRISPomyces & HDR & S. lividans & ACT & - & [50] \\
\hline & redD - redF & Deletion & pCRISPomyces & HDR & S. lividans & RED & - & \\
\hline & redN & Deletion & pCRISPomyces & HDR & S. lividans & RED & - & \\
\hline & $\operatorname{dev} B$ & Deletion & pCRISPomyces & HDR & S. rimosus & - & $\begin{array}{l}\text { Oxytetracycline } \\
\text { production enhancement } \\
\text { by disruption of } \\
\text { competitive gene }\end{array}$ & [93] \\
\hline & zwf2 & Deletion & pCRISPomyces & HDR & S. rimosus & - & $\begin{array}{l}\text { Oxytetracycline } \\
\text { production enhancement } \\
\text { by disruption of } \\
\text { competitive gene }\end{array}$ & \\
\hline & phpD & Deletion & pCRISPomyces & HDR & S. viridochromogenes & $\begin{array}{l}\text { Phosphinothricin } \\
\text { tripeptide }\end{array}$ & - & [50] \\
\hline & phpM & Deletion & pCRISPomyces & HDR & S. viridochromogenes & $\begin{array}{l}\text { Phosphinothricin } \\
\text { tripeptide }\end{array}$ & - & \\
\hline & sceN & Deletion & pCRISPR-Cas9 & HDR & $\begin{array}{l}\text { Streptomyces } \\
\text { sp.SD85 }\end{array}$ & $\begin{array}{l}\text { BGC11 } \\
\text { (sceliphrolactam) }\end{array}$ & - & [18] \\
\hline & sceQ-sceR fusion & Deletion & pCRISPR-Cas9 & HDR & $\begin{array}{l}\text { Streptomyces } \\
\text { sp.SD85 }\end{array}$ & $\begin{array}{l}\text { BGC11 } \\
\text { (sceliphrolactam) }\end{array}$ & $\begin{array}{l}\text { Fusion of sceQ and sce R } \\
\text { by deleting stop codon of } \\
\text { sceQ, intergenic region } \\
\text { between sceQ and sceR, } \\
\text { and start codon of sceR }\end{array}$ & \\
\hline & actI-orf1 & Deletion & pCRISPR-Cas9 & HDR & S. coelicolor & $\mathrm{ACT}$ & - & [86] \\
\hline & actVB & Deletion & pCRISPR-Cas9 & HDR & S. coelicolor & $\mathrm{ACT}$ & - & \\
\hline
\end{tabular}


Table 2. Continued.

\begin{tabular}{|c|c|c|c|c|c|c|c|c|}
\hline Cas & Target & Strategy & Vector & Repair & Organism & $\begin{array}{l}\text { Related secondary } \\
\text { metabolite }\end{array}$ & Remark & Ref \\
\hline \multirow[t]{23}{*}{ SpCas9 } & ACT cluster & Deletion & pKCCas9 & HDR & S. coelicolor & $\mathrm{ACT}$ & - & [42] \\
\hline & actII-orf4 and redD & Deletion & pKCCas9 & HDR & S. coelicolor & ACT and RED & Multiplexed editing & \\
\hline & CDA cluster & Deletion & pKCCas9 & HDR & S. coelicolor & $\mathrm{CDA}$ & - & \\
\hline & $\operatorname{gln} R$ & Deletion & pKCCas9 & HDR & S. coelicolor & - & - & \\
\hline & RED cluster & Deletion & pKCCas9 & HDR & S. coelicolor & RED & - & \\
\hline & redD & Deletion & pKCCas9 & HDR & S. coelicolor & RED & - & \\
\hline & papR3 & Deletion & pKCCas9 & HDR & S. pristinaespiralis & pristinamycin & - & [90] \\
\hline & snaE1 and snaE2 & Deletion & pKCCas9 & HDR & S. pristinaespiralis & pristinamycin & - & \\
\hline & rpsL & $\begin{array}{l}\text { Point } \\
\text { mutation }\end{array}$ & pKCCas9 & HDR & S. coelicolor & - & Lys88Glu mutation & [42] \\
\hline & $\begin{array}{l}\text { ACT, CDA, } \\
\text { CPK, RED } \\
\text { deleted region }\end{array}$ & Replacement & pKCCas9 & HDR & $\begin{array}{l}\text { S. coelicolor M1146, } \\
\text { M1152 }\end{array}$ & - & ФС31 attB integration & [89] \\
\hline & $\begin{array}{l}\text { Non-target } \\
\text { BGCs }\end{array}$ & Replacement & pKCCas9 & HDR & S. pristinaespiralis & $\begin{array}{l}\mathrm{BGC} 2,3,5,13 \text {, and } \\
15\end{array}$ & $\begin{array}{l}\text { Non-target BGC } \\
\text { replacement with ФС } 31 \\
\text { attB or } Ф В T 1 \text { attB site }\end{array}$ & \\
\hline & $\begin{array}{l}\text { indC-like indigoidine } \\
\text { synthase }\end{array}$ & Insertion & pCRISPomyces & HDR & S. albus & Indigoidine & $\begin{array}{l}\text { Kas } \mathrm{O}^{*} \text { promoter knock-in } \\
\text { to activate silent BGCs }\end{array}$ & [87] \\
\hline & actII-orf4 & Insertion & pCRISPomyces & HDR & S. lividans & ACT & $\begin{array}{l}\text { Kas } O^{*} \text { promoter knock-in } \\
\text { to activate silent BGCs }\end{array}$ & \\
\hline & $\begin{array}{l}\text { frbD operon } \\
\text { and frbC } \\
\text { homolog }\end{array}$ & Insertion & pCRISPomyces & HDR & S. roseosporus & FR-900098 & $\begin{array}{l}\text { Kas } \mathrm{O}^{*} \text { promoter knock-in } \\
\text { to activate silent BGCs }\end{array}$ & \\
\hline & main synthase gene & Insertion & pCRISPomyces & HDR & S. roseosporus & BGC3 (T1pks) & $\begin{array}{l}\text { Kas } O^{*} \text { promoter knock-in } \\
\text { to activate silent BGCs }\end{array}$ & \\
\hline & luxR-type regulator & Insertion & pCRISPomyces & HDR & S. roseosporus & BGC18 (T1pks) & $\begin{array}{l}\text { Kas } O^{*} \text { promoter knock-in } \\
\text { to activate silent BGCs }\end{array}$ & \\
\hline & SSGG_RS0133915 & Insertion & pCRISPomyces & HDR & S. roseosporus & $\begin{array}{l}\text { BGC24 } \\
\text { (Nrps-t1pks) }\end{array}$ & $\begin{array}{l}\text { Kas } O^{*} \text { promoter knock-in } \\
\text { to activate silent BGCs }\end{array}$ & \\
\hline & $\begin{array}{l}\text { rppA } \\
\text { and cytochrome } \mathrm{P} 450\end{array}$ & Insertion & pCRISPomyces & HDR & S. venezuelae & BGC16 (T3pks) & $\begin{array}{l}\mathrm{KasO}^{*} \text { promoter knock-in } \\
\text { to activate silent BGCs }\end{array}$ & \\
\hline & $\begin{array}{l}\text { SSQG_RS26895-RS26920 } \\
\text { operon }\end{array}$ & Insertion & pCRISPomyces & HDR & S. viridochromogenes & BGC22 (T2pks) & $\begin{array}{l}\mathrm{KasO}^{*} \text { promoter knock-in } \\
\text { to activate silent BGCs }\end{array}$ & \\
\hline & rkD & Cloning & - & - & - & RK-682 & ICE & [95] \\
\hline & homE & Cloning & - & - & - & Holomycin & ICE & \\
\hline & stuE stuF2 & Cloning & - & - & - & Tü 3010 & ICE & [98] \\
\hline & stuD1, stuD2 & Cloning & - & - & - & Tü 3010 & ICE & \\
\hline
\end{tabular}


Table 2. Continued.

\begin{tabular}{|c|c|c|c|c|c|c|c|c|}
\hline Cas & Target & Strategy & Vector & Repair & Organism & $\begin{array}{l}\text { Related secondary } \\
\text { metabolite }\end{array}$ & Remark & Ref \\
\hline \multirow[t]{5}{*}{ SpCas9 } & Tetarimycin BGC & Cloning & - & - & - & Tetarimycin & mCRISTAR & [97] \\
\hline & $\begin{array}{l}\text { spr1 region } \\
(\mathrm{pglE}-\mathrm{snbC})\end{array}$ & Cloning & - & - & - & Pristinamycin & mCRISTAR & [90] \\
\hline & 5-oxomilbemycin BGC & Cloning & - & - & - & 5-oxomilbemycin & mCRISTAR & [99] \\
\hline & $\begin{array}{l}\text { Jadomycin and } \\
\text { chlortetracycline BGC }\end{array}$ & Cloning & - & - & - & $\begin{array}{l}\text { Jadomycin, and } \\
\text { chlortetracycline }\end{array}$ & $\mathrm{CATCH}$ & [96] \\
\hline & $\begin{array}{l}\text { Chloramphenicol, YM- } \\
\text { 216391, and pristinamycin } \\
\text { II BGCs }\end{array}$ & Cloning & - & - & - & $\begin{array}{l}\text { Chloramphenicol, } \\
\text { YM-216391, and } \\
\text { pristinamycin }\end{array}$ & $\begin{array}{l}\text { CRISPR/Cas9 cleavage } \\
\text { and Gibson assembly }\end{array}$ & [89] \\
\hline \multirow[t]{10}{*}{ SpdCas9 } & actI-orf1 & CRISPRi & pCRISPR-dCas9 & - & S. coelicolor & ACT & - & {$[86]$} \\
\hline & actI-orf1 & CRISPRi & pSET-dCas9 & - & S. coelicolor & $\mathrm{ACT}$ & - & [101] \\
\hline & actII-orf4 & CRISPRi & pSET-dCas9 & - & S. coelicolor & $\mathrm{ACT}$ & - & \\
\hline & cdaPS1 & CRISPRi & pSET-dCas9 & - & S. coelicolor & CDA & - & \\
\hline & cpkA & CRISPRi & pSET-dCas9 & - & S. coelicolor & CPK & - & \\
\hline & redQ & CRISPRi & pSET-dCas9 & - & S. coelicolor & RED & - & \\
\hline & actI-orf1 and cdaPS1 & CRISPRi & pSET-dCas9 & - & S. coelicolor & $\mathrm{ACT}, \mathrm{CDA}$ & Multiplexed editing & \\
\hline & $\begin{array}{l}\text { actI-orf1 and } \\
\text { cdaPS1, cpkA }\end{array}$ & CRISPRi & pSET-dCas9 & - & S. coelicolor & $\begin{array}{l}\mathrm{ACT}, \mathrm{CDA} \text {, and } \\
\mathrm{CPK}\end{array}$ & Multiplexed editing & \\
\hline & $\begin{array}{l}\text { actI-orf1, cdaPS1, and } \\
\text { cpkA, redQ }\end{array}$ & CRISPRi & pSET-dCas9 & - & S. coelicolor & $\begin{array}{l}\mathrm{ACT}, \mathrm{RED}, \mathrm{CDA} \text {, } \\
\text { and } \mathrm{CPK}\end{array}$ & Multiplexed editing & \\
\hline & $\begin{array}{l}\text { Proteins with AmiR and } \\
\text { NasR Transcriptional } \\
\text { Antiterminator Regulator } \\
\text { domain (ANTAR) }\end{array}$ & CRISPRi & pSET-dCas 9 & - & S. coelicolor & - & Gene essentiality test & \\
\hline & redX & Disruption & pKCCpf1 & NHEJ & S. coelicolor & RED & - & \\
\hline & redX & Disruption & pKCCpf1 & NHEJ & S. coelicolor & RED & $\begin{array}{l}\text { Reconstituted NHEJ with } \\
\text { ligD and Ku expression }\end{array}$ & \\
\hline & redX, redG & Deletion & pKCCpf1 & NHEJ & S. coelicolor & RED & $\begin{array}{l}\text { Deletion by reconstituted } \\
\text { NHEJ with ligD and } \mathrm{Ku} \\
\text { expression at two } \\
\text { cleavage sites }\end{array}$ & \\
\hline & actI-orfI & Deletion & pKCCpf1 & HDR & S. coelicolor & $\mathrm{ACT}$ & - & \\
\hline & $\operatorname{redX}$ & Deletion & pKCCpf1 & HDR & S. coelicolor & RED & - & \\
\hline & actI-orf1, redX & Deletion & pKCCpf1 & HDR & S. coelicolor & $\mathrm{ACT}$ and RED & Multiplexed editing & \\
\hline & SBI00792 & Deletion & pKCCpf1 & HDR & S. hygroscopicus & $\begin{array}{l}\text { Adjacent to } \\
\text { 5-oxomilbemycin }\end{array}$ & - & \\
\hline & actI-orf1 & CRISPRi & pSETddCpf1 & - & S. coelicolor & $\mathrm{ACT}$ & - & \\
\hline & $\operatorname{redX}$ & CRISPRi & pSETddCpf1 & - & S. coelicolor & RED & - & \\
\hline \multirow[t]{2}{*}{ FnddCpf1 } & cpkA & CRISPRi & pSETddCpf1 & - & S. coelicolor & CPK & - & \\
\hline & $\begin{array}{l}\text { redX, actI-orf1, } \\
\text { and cpkA }\end{array}$ & CRISPRi & pSETddCpf1 & - & S. coelicolor & $\begin{array}{l}\text { RED, ACT, } \\
\text { and CPK }\end{array}$ & Multiplexed editing & \\
\hline
\end{tabular}


resolution of Tn mutagenesis is relatively low, and thus insufficient for screening of essential Streptomyces genes [102]. The CRISPRi-based screening will enable highthroughput identification of essential genes and provide invaluable resources for the construction of genomereduced chassis for efficient production of secondary metabolites via heterologous expression $[103,104]$.

\section{Cpf1 as an Alternative to Cas9}

Since SpCas9 recognizes 5'-NGG as the PAM sequence, there are considerable target sites in the GC-rich Streptomyces genome [85]. However, AT-rich regions in the Streptomyces genome are not targetable by the CRISPR/SpCas9 system, limiting precise engineering of the desired genomic locus. To overcome this limitation, another Cas enzyme from Francisella novicida, FnCpf1, has been introduced to Streptomyces as an alternative genome engineering tool. FnCpf1 recognizes 5'-TTV as the PAM sequence, and thus is suitable for targeting AT-rich regions, further elevating the potential of CRISPR/Cas-based genome engineering in Streptomyces [105]. Based on CRISPR/Cpf1, successful applications, including NHEJ, reconstituted NHEJ and HDRmediated genome editing, have been made in Streptomyces [106]. In addition to genome editing, transcriptional repression based on DNase-deactivated Cpf1 (ddCpf1) has been applied in Streptomyces, successfully covering all applications of CRISPR/Cas9 for Streptomyces [106]. Cpf1 not only expands the potential targets for CRISPR/Cas mediated genome engineering, but it also broadens the range of CRISPR/Cas applicable organisms with less cellular toxicity compared to Cas9 [106]. However, in vitro applications of the CRISPR/Cpf1 system have not been described for SM-BGC cloning in Streptomyces. Unlike Cas9, Cpf1 generates a DSB with sticky ends, which may enable efficient directional cloning with simple ligation [105].

\section{Heterologous Expression of Secondary Metabolite Biosynthetic Gene Clusters}

Compared to secondary metabolite production in the native host, heterologous expression has several advantages, including: (1) it enables SM-BGCs expression of unculturable or slow-growing native host strains, (2) it overcomes the difficult genetic manipulation of the native host, and (3) it bypasses the innate regulatory network of the native host [107]. In fact, the Streptomyces species is the most suitable host for heterologous expression of SM-BGCs, as compared to other organisms such as E. coli, bacillus, or yeast, because of its (1) abundant precursors, cofactors, and enzymes for secondary metabolite biosynthesis; (2) sophisticated postmodification system for secondary metabolites such as phosphorylation, acetylation, farnesylation, and glycosylation; (3) broad antibiotic resistance and tolerance; (4) proper protein folding for the functionality of multi-enzyme complexes; and (5) other cellular environments, including $\mathrm{pH}$ and redox potential [108]. Over the past few decades, approximately 100 SM-BGCs have been heterologously expressed in Streptomyces, particularly in S. coelicolor, S. lividans, S. avermitilis, and S. albus [109]. Although heterologous expression has been successfully used for secondary metabolite production, several limitations still remain. First, the large size of SM-BGC hampers the efficiency of genetic manipulation [110]. Further, even if the transfer of SM-BGCs to the heterologous expression host was successful, their expression may be insignificant due to differences in the precursor pool from that of the native host and metabolic competitions between the target SM-BGC and other endogenous SM-BGCs in the expression host [108]. In this subsection, we discuss cloning strategies for large-size SM-BGCs and optimization of the heterologous expression host.

There are four steps to express the SM-BGC in the heterologous expression host, which include (1) acquisition of the target SM-BGC from the native host genome, (2) ligation or assembly of the SM-BGC to the vector, (3) transfer of the SM-BGC-encoded vector to the heterologous expression host, and (4) target of secondary metabolite production (Table 3 ).

The most frequently used method for acquisition of the target SM-BGC is the genomic library construction using cosmid, fosmid, BAC, and PAC vectors [109]. This method can be applied to a broad range of Streptomyces genomes, in which the full sequence is unknown. It is particularly effective to discover novel secondary metabolites from the metagenome, including unculturable bacteria [111]. The second method is to cut both ends of the target SM-BGC from the genomic DNA. However, restriction sites are not generally available at both ends of target SM-BGCs. Thus, unique restriction sites can be introduced using a suicide plasmid, which contains a homologous sequence of one of the end sites, and integrated into both ends of target SMBGCs by single crossover. Streptomyces bacterial artificial chromosome system (pSBAC) is a successful example for some SM-BGCs, such as tautomycetin $(80 \mathrm{~kb})$ and pikromycin $(60 \mathrm{~kb})[112,113]$. Another strategy is the integrase-mediated recombination (IR) system that introduces integration sites, such as att $_{6}$ and att $_{9}$, at both ends by single crossover 
Table 3. Different strategy for BGC cloning.

\begin{tabular}{|c|c|c|c|}
\hline BGC cloning steps & Strategies & Representative examples & Ref \\
\hline \multirow{5}{*}{$\begin{array}{l}\text { Acquisition of the target BGC } \\
\text { from the native host genome }\end{array}$} & Genomic library & Cosmid, fosmid, BAC, and PAC & [135] \\
\hline & \multirow{3}{*}{$\begin{array}{l}\text { Cut off both ends } \\
\text { of target BGC }\end{array}$} & Restriction: pSBAC & [113] \\
\hline & & Integrase: IR & [114] \\
\hline & & CRISPR: CATCH, mCRISTAR, and CRISPR-TAR & {$[96,97,120]$} \\
\hline & PCR amplification & DNA assembler & [116] \\
\hline \multirow{6}{*}{$\begin{array}{l}\text { Ligation or assembly of the } \\
\text { target BGC to the vector }\end{array}$} & \multirow[t]{3}{*}{ In vitro } & Sticky end ligation: pSBAC & [113] \\
\hline & & Blunt end ligation: ICE & [95] \\
\hline & & Gibson assembly: CATCH and MSGE & {$[89,96]$} \\
\hline & \multirow[t]{3}{*}{ In vivo } & Recombination in native host: IR & [114] \\
\hline & & Recombination in E. coli: LLHR & [117] \\
\hline & & $\begin{array}{l}\text { Recombination in yeast: TAR, DNA assembler, } \\
\text { DiPac, and mCRISTAR }\end{array}$ & $\begin{array}{l}{[97,115,116,} \\
118]\end{array}$ \\
\hline \multirow{2}{*}{$\begin{array}{l}\text { Transferring BGC vector to the } \\
\text { expression host }\end{array}$} & Conjugation & pUWLcre & [136] \\
\hline & Protoplast transformation & pSKC2 and pOJ446 & [137] \\
\hline \multirow{2}{*}{$\begin{array}{l}\text { Target secondary metabolite production } \\
\text { by expression of the BGC vector }\end{array}$} & Integrative & pSET152, pCAP01, and pESAC & {$[118,138]$} \\
\hline & Replicative & pSKC2 and pUWL201 & [139] \\
\hline
\end{tabular}

homologous recombination of the vector, such as pKC1139 [114]. Ф-integrase-mediated excision of the target SM-BGC is subsequently performed to obtain the SM-BGC vector in vivo. Recently, in vitro site-specific digestion of genomic DNA using the CRISPR/Cas9 system was used as an alternative strategy for the acquisition of target SM-BGCs [94-97, 115]. The third method for acquisition of target SMBGCs is PCR amplification [116], in which each fragment has homologous arms at both ends added by PCR primers to self-assemble or assemble together with genetic parts such as promoters and RBSs. As all three SM-BGC acquisition methods have their own advantages and limitations, they should be applied according to specific situations.

Ligation or assembly methods of target SM-BGC to the heterologous expression vector can be largely divided into two groups, in vitro and in vivo. In vitro cloning of the target SM-BGCs involves (1) ligation of cognate sticky ends formed by restriction enzyme digestion or two CRISPR/ Cas9 digestion using T4 DNA ligase [95, 109] and (2) Gibson assembly using 5' exonuclease [89, 96]. Ligation of two fragments by DNA ligase is simple and efficient, but preparation of cognate ends for ligation is required. Conversely, the Gibson assembly method is theoretically universal for any fragments by introduction of homologous sequence at their ends through PCR amplification. In vivo cloning of SM-BGCs exploits the homologous recombination system in the native host [114], E. coli [117], and yeast [118]. For example, integrase-mediated recombination (IR) directly obtains the SM-BGC-containing vector from the genomic DNA of the native host [114]. Linear-linear homologous recombination (LLHR) using $\lambda$-Red system or RecET system in $E$. coli is one of the most widely used in vivo recombination systems with high cloning efficiency, but their reported size limit is about $50 \mathrm{~kb}$ [107, 109, 117]. Unlike bacteria, yeast have their own efficient homologous recombination system, such that more than two large fragments can be assembled by transformation of all fragments simultaneously into yeast, which is named as transformation-associated recombination (TAR) [119]. The TAR cloning method has shown relatively higher efficiency, size capacity, and number of fragments in many strategies such as CRISPR-TAR, mCRISTAR, and DNA assembler, compared to other in vivo cloning methods [97, 116, 120]. Thus, TAR and in vitro Gibson assembly are considered as the most high-throughput and efficient strategies for the preparation of Streptomyces SM-BGCs vectors.

In most cases, constructed SM-BGC vectors have been transformed to the heterologous expression host through conjugation between E. coli and Streptomyces strains [109]. Otherwise, the vector can be directly transformed to the heterologous expression host by the protoplast method [32], which depends on the vector components such as oriT (essential for conjugation) and the Streptomyces species. After transfer of the SM-BGC vector to the expression host, the SM-BGC vector can be integrated into the host genome or remain as a replicative plasmid. Most heterologous 
expression vectors in previous studies were integrative vectors, which are more stable after serial generations [109]. Genetic stability is very important for the further fermentation process of secondary metabolites [121]. However, the copy number of the integrative SM-BGC vector is only one compared to multi-copy replicative vectors. Therefore, multi-copy integration of the SM-BGC vector into genome or promoter refactoring of SM-BGC genes should be additionally performed to increase productivity [89]. Thus far, many SM-BGC cloning strategies for heterologous expression have been developed. However, cloning of a large size and number of SM-BGC fragments is a common limitation. Therefore, a high-throughput, stepwise, systematic strategy for efficient cloning of SM-BGCs for heterologous expression should be considered.

\section{Streptomyces Chassis Strains for Heterologous Gene Expression}

To improve yields of secondary metabolites, Streptomyces hosts were genetically modified by removing endogenous SM-BGCs, nonessential genes, and genomic regions and engineering genes with pleiotropic functions. Representative examples of optimized Streptomyces as heterologous expression hosts are shown in Table 4. Removing SM-BGCs resulted in a "reduced Streptomyces genome," which can conserve energy and other building blocks in addition to the specific precursor pool. In other words, the nucleotide and energy for replication of the reduced genome will be decreased, and this redundant energy can be used for the target metabolite production. Indeed, several engineered strains of S. coelicolor (4 SM-BGCs deletion), S. lividans (3 SM-BGCs deletion), and S. albus (15 SM-BGCs deletion) have shown improved target secondary metabolite production and reduced background chemical profiles [104, 122-124].

Nonessential genomic regions (NGR) are usually located at the ends of linear chromosomes, which are not conserved in all species and dispensable for cell growth. They include genomic islands (GI), IS elements, and endogenous CRISPR array regions that decrease genomic stability. For example, NGRs in S. avermitilis $(1.48 \mathrm{Mb})$ and S. chattanoogenisis $(0.7 \mathrm{Mb})$ were selected, based on comparative genomics of Streptomyces genomes, and deleted by $\lambda$-Red system or Cre/loxP recombination system [121, 125]. As expected, deletion of NGRs increased the fitness level of the engineered strain relative to the wild-type strain with beneficial effects on morphology, ATP level, NADPH level, transformation efficiency, and genetic stability in S. chattanoogenisis [121].
However, large deletion of NGRs may cause undesired deleterious effects on cell growth due to the unknown essential function of genes and synthetic lethality of more than two abundant essential genes. Therefore, the systems level of functional genomic studies should be followed to determine the nonessential regions more precisely. Integration of these functional studies with multi-omics data and experimental validations might allow construction of a highly efficient Streptomyces chassis strain for heterologous expression of SM-BGCs [126, 127].

Genes with pleiotropic functions can be additionally engineered to improve productivity of target secondary metabolites. For instance, deletion of phosphofructokinase gene $p f k$ and global transcriptional regulator gene $w b l A$ and overexpression of global transcriptional regulator gene $\mathrm{crp}$ in S. albus increased secondary metabolite production, redox potential, and fitness by changing the global transcriptional status [128]. Further, point mutations of RNA polymerase gene $r p o B$ and ribosomal protein gene $r p s L$ in $S$. coelicolor showed increased fitness and secondary metabolite production by altering regulation at both the transcriptional and translational levels [104]. As pleiotropic functions usually include undesired phenotypes for secondary metabolite production, the engineering target should be selected carefully through rational design based on systematic information.

\section{Future Perspective}

In this review, we summarized a synthetic biology strategy to produce novel secondary metabolites in Streptomyces. Accumulation of genetic information and SM-BGCs aided by recent advances in Next-Generation Sequencing (NGS) has revealed the enormous potential of Streptomyces as a reservoir for novel bioactive compounds and is far outpacing our capacity to explore SM-BGCs and their products [129]. To fully harness Streptomyces' ability to produce valuable secondary metabolites, rational design and efficient synthetic biology tools for Streptomyces are essential. To date, however, in silico SM-BGC prediction tools, such as antiSMASH, still need to be optimized for precise mining capability. Further, synthetic biology tools for Streptomyces are limited to fulfill the precise designs for novel secondary metabolite production. To this end, integration of massive omics data and vigorous functional studies can elevate the fidelity of SM-BGC mining and increase genetic parts for Streptomyces engineering. Specifically, construction of genetic part libraries based on transcriptome and translatome data by screening using a 
Table 4. Representative examples of Streptomyces chassis strain for optimal heterologous expression.

\begin{tabular}{|c|c|c|c|c|c|c|c|c|}
\hline $\begin{array}{l}\text { Heterologous } \\
\text { host }\end{array}$ & Engineering & $\begin{array}{l}\text { Target genes } \\
\text { or regions }\end{array}$ & Deletion method & Expressed BGC & BGC vector & Effect & Limitation & Ref \\
\hline $\begin{array}{l}\text { Streptomyces } \\
\text { coelicolor } \\
\text { M145 }\end{array}$ & $\begin{array}{l}\text { BGC } \\
\text { deletion and } \\
\text { Pleiotropic } \\
\text { gene } \\
\text { engineering }\end{array}$ & $\begin{array}{l}\text { Deletion of four } \\
\text { BGCs (ACT, RED, } \\
\text { CPK, and CDA) } \\
\text { Point mutations of } \\
\text { rpoB and rpsL. }\end{array}$ & $\begin{array}{l}\text { Homologous } \\
\text { recombination by } \\
\text { double crossover of } \\
\text { the plasmid }\end{array}$ & $\begin{array}{l}\text { Shlorampheniocol and } \\
\text { congocidine }\end{array}$ & Cosmid & $\begin{array}{l}\text { Improved } \\
\text { production, clean } \\
\text { profile of } \\
\text { background } \\
\text { metabolites }\end{array}$ & Low fitness & [104] \\
\hline $\begin{array}{l}\text { Streptomyces } \\
\text { sp. FR-008 }\end{array}$ & $\begin{array}{l}\text { BGC } \\
\text { deletion }\end{array}$ & $\begin{array}{l}\text { Deletion of three } \\
\text { BGCs (candicidin, } \\
\text { type III PKS, and } \\
\text { type I PKS) }\end{array}$ & $\begin{array}{l}\text { Homologous } \\
\text { recombination by } \\
\text { double crossover of } \\
\text { the plasmid }\end{array}$ & None & None & $\begin{array}{l}\text { Improved fitness, } \\
\text { sporulation, and } \\
\text { clean profile of } \\
\text { background } \\
\text { metabolites }\end{array}$ & $\begin{array}{l}\text { Heterologous } \\
\text { expression was } \\
\text { not tested }\end{array}$ & [124] \\
\hline $\begin{array}{l}\text { Streptomyces } \\
\text { lividans TK24 }\end{array}$ & $\begin{array}{l}\text { BGC } \\
\text { deletion }\end{array}$ & $\begin{array}{l}\text { Deletion of three } \\
\text { BGCs (ACT, RED, } \\
\text { and CDA) } \\
\text { One copy } \\
\text { integration of AfsRS } \\
\text { by attB integrase }\end{array}$ & $\begin{array}{l}\text { Homologous } \\
\text { recombination by } \\
\text { double crossover of } \\
\text { the plasmid }\end{array}$ & $\begin{array}{l}\text { Streptothiricins, borrelidin, } \\
\text { and linear lipopeptides }\end{array}$ & BAC & $\begin{array}{l}\text { High-throughput } \\
\text { functional genome } \\
\text { mining of } \\
\text { Streptomyces rochei }\end{array}$ & $\begin{array}{l}\text { Low fitness, } \\
\text { laborious } \\
\text { screening of } \\
\text { BAC libraries }\end{array}$ & [123] \\
\hline $\begin{array}{l}\text { Streptomyces } \\
\text { lividans TK24 }\end{array}$ & $\begin{array}{l}\text { BGC } \\
\text { deletion }\end{array}$ & $\begin{array}{l}\text { Deletion of three } \\
\text { BGCs (ACT, RED, } \\
\text { and CDA) } \\
\text { Additional copies } \\
\text { integration of AfsRS } \\
\text { by attB integrase }\end{array}$ & $\begin{array}{l}\text { Homologous } \\
\text { recombination by } \\
\text { double crossover of } \\
\text { the plasmid }\end{array}$ & Hybrubins & $\mathrm{BAC}$ & $\begin{array}{l}\text { High-throughput } \\
\text { functional genome } \\
\text { mining of } \\
\text { Streptomyces variabilis } \\
\text { Pathway crosstalk } \\
\text { between } \\
\text { incompletely deleted } \\
\text { RED cluster. }\end{array}$ & Low fitness & [140] \\
\hline $\begin{array}{l}\text { Streptomyces } \\
\text { albus J1074 }\end{array}$ & $\begin{array}{l}\text { BGC } \\
\text { deletion }\end{array}$ & $\begin{array}{l}\text { Deletion of fifteen } \\
\text { BGCs (Frontalamide, } \\
\text { Paulomycin, } \\
\text { Geosmin, } \\
\text { Lantibiotic, } \\
\text { carotenoid, flaviolin, } \\
\text { candicidin, } \\
\text { antimycin, } 2 \text { PKS- } \\
\text { NRPS, and } 4 \text { NRPS) }\end{array}$ & $\begin{array}{l}\text { Homologous } \\
\text { recombination by } \\
\text { double crossover of } \\
\text { the plasmid using } \\
\lambda \text {-red system }\end{array}$ & $\begin{array}{l}\text { Tunicamycin B2, } \\
\text { moenomycin M, } \\
\text { griseorhodin A, } \\
\text { pyridinopyrone A, } \\
\text { bhimamycin A, } \\
\text { didesmethylmensacarcin, } \\
\text { didemethoxyaranciamycino } \\
\text { ne, aloesaponarin II, and } \\
\text { cinnamycin, fralnimycin }\end{array}$ & $\begin{array}{l}\text { Fosmid } \\
\text { and BAC }\end{array}$ & $\begin{array}{l}\text { Improved } \\
\text { production, clean } \\
\text { profile of } \\
\text { background } \\
\text { metabolites }\end{array}$ & $\begin{array}{l}\text { Moenomycin M } \\
\text { productivity } \\
\text { was reduced. }\end{array}$ & [122] \\
\hline $\begin{array}{l}\text { Streptomyces } \\
\text { avermitilis }\end{array}$ & $\begin{array}{l}\text { Nonessential } \\
\text { region } \\
\text { deletion } \\
\text { and BGC } \\
\text { deletion }\end{array}$ & $\begin{array}{l}\text { Deletion of } 1.48 \mathrm{Mb} \\
\text { left arm determined } \\
\text { by comparative } \\
\text { genomics }\end{array}$ & $\begin{array}{l}\text { Homologous } \\
\text { recombination by } \\
\text { double crossover of } \\
\text { the plasmid using } \\
\lambda \text {-red system } \\
\text { Cre/loxP system }\end{array}$ & $\begin{array}{l}\text { Streptomycin, cephamycin } \\
\mathrm{C} \text {, and pladienolide }\end{array}$ & $\begin{array}{l}\text { Cosmidand } \\
\text { BAC }\end{array}$ & $\begin{array}{l}\text { Improved } \\
\text { production by } \\
\text { additional } \\
\text { introduction of } \\
\text { regulatory gene and } \\
\text { optimization of } \\
\text { codon usage }\end{array}$ & $\begin{array}{l}\text { Low } \\
\text { conjugation } \\
\text { efficiency }\end{array}$ & [103] \\
\hline $\begin{array}{l}\text { Streptomyces } \\
\text { avermitilis }\end{array}$ & $\begin{array}{l}\text { Nonessential } \\
\text { region } \\
\text { deletion }\end{array}$ & $\begin{array}{l}\text { Deletion of } 1.48 \mathrm{Mb} \\
\text { left arm and some } \\
\text { regions determined } \\
\text { by comparative } \\
\text { genomics }\end{array}$ & $\begin{array}{l}\text { Homologous } \\
\text { recombination by } \\
\text { double crossover of } \\
\text { the plasmid using } \\
\lambda \text {-red system } \\
\text { Cre/loxP system }\end{array}$ & $\begin{array}{l}\text { Streptomycin, ribostamycin, } \\
\text { kasugamycin, pholipomycin, } \\
\text { oxytetracycline, } \\
\text { resistomycin, pladienolide B, } \\
\text { erythromycin A, } \\
\text { bafilimycin B1, nemadectin } \alpha \text {, } \\
\text { aureothin, leptomycin, } \\
\text { cephamycin C, holomycin, } \\
\text { lactacystin, clavulanic acid, } \\
\text { rebeccamycin, novobiocin, } \\
\text { chloramphenicol, } \\
\text { 2-methylisoborneol, } \\
\text { pentalenolactone, } \\
\text { amorpha-1,4-diene, } \\
\text { taxa-4,11-diene, } \\
\text { levopimaradiene, and } \\
\text { abietatriene }\end{array}$ & $\begin{array}{l}\text { Cosmid } \\
\text { and BAC }\end{array}$ & $\begin{array}{l}\text { Improved } \\
\text { production, fitness, } \\
\text { clean profile of } \\
\text { background } \\
\text { metabolites. Broad } \\
\text { precursor capacity } \\
\text { (sugar, polyketide, } \\
\text { peptide, shikimate, } \\
\text { and MVA or MEP) }\end{array}$ & $\begin{array}{l}\text { Ribostamycin, } \\
\text { oxytetracycline } \\
\text { productivity } \\
\text { were reduced }\end{array}$ & [125] \\
\hline
\end{tabular}


Table 4. Continued.

\begin{tabular}{|c|c|c|c|c|c|c|c|c|}
\hline $\begin{array}{l}\text { Heterologous } \\
\text { host }\end{array}$ & Engineering & $\begin{array}{c}\text { Target genes } \\
\text { or regions }\end{array}$ & Deletion method & Expressed BGC & BGC vector & Effect & Limitation & Ref \\
\hline $\begin{array}{l}\text { Streptomyces } \\
\text { chattanoogensis } \\
\text { L10 }\end{array}$ & $\begin{array}{l}\text { Nonessential } \\
\text { region } \\
\text { deletion }\end{array}$ & $\begin{array}{l}\text { Deletion of } 1.3 \mathrm{Mb} \\
\text { and } 0.7 \mathrm{Mb} \\
\text { nonessential arms } \\
\text { determined by } \\
\text { comparative } \\
\text { genomics and } \\
\text { prediction tools }\end{array}$ & $\begin{array}{l}\text { Cre/loxP } \\
\text { recombination }\end{array}$ & ACT & pMM1 & $\begin{array}{l}\text { Improved } \\
\text { production, fitness, } \\
\text { ATP, NADPH, } \\
\text { transformation } \\
\text { efficiency, and } \\
\text { genetic stability. } \\
\text { Dispersed } \\
\text { morphology. }\end{array}$ & $\begin{array}{l}1.3 \mathrm{Mb} \text { deleted } \\
\text { strain was } \\
\text { detrimental } \\
\text { due to deletion } \\
\text { of some } \\
\text { unknown genes }\end{array}$ & [121] \\
\hline $\begin{array}{l}\text { Streptomyces } \\
\text { albus J1074 }\end{array}$ & $\begin{array}{l}\text { Pleiotropic } \\
\text { gene } \\
\text { engineering } \\
\text { and BGC } \\
\text { deletion }\end{array}$ & $\begin{array}{l}\text { Deletion of } p f k, w b l A \text {, } \\
\text { overexpression of } \\
c p k \text {, and deletion of } \\
\text { one BGC } \\
\text { (paulomycin) }\end{array}$ & $\begin{array}{l}\text { Homologous } \\
\text { recombination by } \\
\text { double crossover of } \\
\text { the plasmid using } \\
\lambda \text {-red system }\end{array}$ & $\mathrm{ACT}$ & Fosmid & $\begin{array}{l}\text { Improved } \\
\text { production, fitness, } \\
\text { and NADPH. }\end{array}$ & $\begin{array}{l}\text { Undesirable } \\
\text { effects might be } \\
\text { incurred due to } \\
\text { the global } \\
\text { change of } \\
\text { transcriptome }\end{array}$ & [128] \\
\hline
\end{tabular}

high-throughput reporter system will deliver a universal set of genetic parts for Streptomyces.

Although genetic tools based on the CRISPR/Cas system have offered diverse strategies to enhance secondary metabolite production and activate silent SM-BGCs [87, 89, 90, 93, 99], further optimization of the CRISPR/Cas system for Streptomyces is still required. An example is that the toxicity of Cas nucleases is disadvantageous for multiplexed applications and CRISPR/Cas bearing systems. In addition, expansion of PAM recognition is required to enable efficient genome engineering. These limitations can be overcome by modulating Cas expression and exploiting Cas variants [106, 130,131]. Particularly, CRISPR activation (CRISPRa) has not been applied to Streptomyces [132]. The CRISPRa approach can serve as an efficient strategy to investigate silent SM-BGCs without labor-intensive genome editing efforts. Multiplexing the precise transcriptional regulation through integration of both CRISPRa and CRISPRi is expected to reconstruct the metabolic network to enhance the precursor supply, reducing flux toward competing pathways or unwanted by-products, bypassing gene expression regulation, and expressing the SM-BGCs. Recently, toehold-gated gRNA was developed, which links endogenous signals to activation of the CRISPR/Cas system [133]. As the production of secondary metabolites requires sufficient accumulation of precursors and activation of biosynthetic genes, the combination of toehold-gated gRNA and CRISPRa and CRISPRi strategies will suggest a new metabolic engineering approach, linking the production of precursors to production of secondary metabolites.

Development of synthetic biology tools can also be exploited to construct the Streptomyces chassis for heterologous expression of novel SM-BGCs. So far, S. albus
J1074 with deletion of 15 BGCs and S. chattanoogensis L10 with deletion of $0.7 \mathrm{Mb}$ of a nonessential arm seem to be the best Streptomyces chassis for heterologous expression [121, 122]. A further challenge might be the construction of the "superhost Streptomyces chassis" by removing all endogenous SM-BGCs, nonessential genes, and genomic regions and adding all precursor synthetic genes. By heterologous expression of the target SM-BGC in this superhost chassis, productivity of target secondary metabolites will be further improved. In addition, novel secondary metabolites will be discovered from a wide array of silent SM-BGCs in a high-throughput manner. However, construction of a superhost for all secondary metabolites might not be feasible due to precursor differences in Streptomyces species. Indeed, all five types of secondary metabolites were produced in the S. albus J1074 strain; however, some metabolites were not produced significantly [122]. Therefore, construction of several "specialized Streptomyces chassis hosts" for each type of secondary metabolite might be a better choice [108]. This "design-build-test (DBT)" cycle, which is a rational design based on in silico SM-BGC mining, the build of a SM-BGC expression in Streptomyces chassis, and the high-throughput test of secondary metabolite production will be iterated to learn and optimize production of novel secondary metabolites (Fig. 1). This synthetic biology strategy will ultimately expand the productivity and diversity of available novel secondary metabolites as potential biopharmaceuticals.

\section{Acknowledgments}

This work was supported by a grant from the Novo Nordisk Foundation (grant number NNF10CC1016517). 
This research was also supported by the Basic Science Research Program (2018R1A1A3A04079196 to S.C.), the Basic Core Technology Development Program for the Oceans and the Polar Regions (2016M1A5A1027458 to B.K.C.), and the Bio \& Medical Technology Development Program (2018M3A9F3079664 to B.-K.C.) through the National Research Foundation (NRF) funded by the Ministry of Science and ICT.

\section{Conflict of Interest}

The authors have no financial conflicts of interest to declare.

\section{References}

1. Ohnishi Y, Ishikawa J, Hara H, Suzuki H, Ikenoya M, Ikeda $\mathrm{H}$, et al. 2008. Genome sequence of the streptomycinproducing microorganism Streptomyces griseus IFO 13350. J. Bacteriol. 190: 4050-4060.

2. Khan ST, Komaki H, Motohashi K, Kozone I, Mukai A, Takagi M, et al. 2011. Streptomyces associated with a marine sponge Haliclona sp.; biosynthetic genes for secondary metabolites and products. Environ. Microbiol. 13: 391-403.

3. Onaka H. 2017. Novel antibiotic screening methods to awaken silent or cryptic secondary metabolic pathways in actinomycetes. J. Antibiot. (Tokyo) 70: 865-870.

4. Lim FY, Sanchez JF, Wang CC, Keller NP. 2012. Toward awakening cryptic secondary metabolite gene clusters in filamentous fungi. Methods Enzymol. 517: 303-324.

5. Medema MH, Alam MT, Breitling R, Takano E. 2011. The future of industrial antibiotic production: from random mutagenesis to synthetic biology. Bioeng. Bugs. 2: 230-233.

6. Nguyen QT, Merlo ME, Medema MH, Jankevics A, Breitling R, Takano E. 2012. Metabolomics methods for the synthetic biology of secondary metabolism. FEBS Lett. 586: 2177-2183.

7. Yang YH, Song E, Lee BR, Kim EJ, Park SH, Kim YG, et al. 2010. Rapid functional screening of Streptomyces coelicolor regulators by use of a $\mathrm{pH}$ indicator and application to the MarR-like regulator AbsC. Appl. Environ. Microbiol. 76: 3645-3656.

8. Myronovskyi M, Luzhetskyy A. 2016. Native and engineered promoters in natural product discovery. Nat. Prod. Rep. 33: 1006-1019.

9. Ziemert N, Alanjary M, Weber T. 2016. The evolution of genome mining in microbes - a review. Nat. Prod. Rep. 33: 988-1005.

10. Harrison J, Studholme DJ. 2014. Recently published Streptomyces genome sequences. Microb. Biotechnol. 7: 373-380.

11. Bentley SD, Chater KF, Cerdeno-Tarraga AM, Challis GL, Thomson NR, James KD, et al. 2002. Complete genome sequence of the model actinomycete Streptomyces coelicolor A3(2). Nature 417: 141-147.

12. Komaki H, Sakurai K, Hosoyama A, Kimura A, Igarashi $Y$, Tamura T. 2018. Diversity of nonribosomal peptide synthetase and polyketide synthase gene clusters among taxonomically close Streptomyces strains. Sci. Rep. 8: 6888.

13. Starcevic A, Zucko J, Simunkovic J, Long PF, Cullum J, Hranueli D. 2008. ClustScan: an integrated program package for the semi-automatic annotation of modular biosynthetic gene clusters and in silico prediction of novel chemical structures. Nucleic Acids Res. 36: 6882-6892.

14. Li MH, Ung PM, Zajkowski J, Garneau-Tsodikova S, Sherman DH. 2009. Automated genome mining for natural products. BMC Bioinformatics 10: 185.

15. Skinnider MA, Dejong CA, Rees PN, Johnston CW, Li H, Webster AL, et al. 2015. Genomes to natural products prediction informatics for secondary metabolomes (PRISM). Nucleic Acids Res. 43: 9645-9662.

16. Blin K, Wolf T, Chevrette MG, Lu X, Schwalen CJ, Kautsar SA, et al. 2017. antiSMASH 4.0-improvements in chemistry prediction and gene cluster boundary identification. Nucleic Acids Res. 45: W36-W41.

17. Weber T, Kim HU. 2016. The secondary metabolite bioinformatics portal: computational tools to facilitate synthetic biology of secondary metabolite production. Synth. Syst. Biotechnol. 1: 69-79.

18. Low ZJ, Pang LM, Ding Y, Cheang QW, Le Mai Hoang K, Thi Tran H, et al. 2018. Identification of a biosynthetic gene cluster for the polyene macrolactam sceliphrolactam in a Streptomyces strain isolated from mangrove sediment. Sci. Rep. 8: 1594.

19. Jia N, Ding MZ, Luo H, Gao F, Yuan YJ. 2017. Complete genome sequencing and antibiotics biosynthesis pathways analysis of Streptomyces lydicus 103. Sci. Rep. 7: 44786.

20. Zhang G, Yu D, Sang B, Feng J, Han L, Zhang X. 2017. Genome-wide analysis reveals the secondary metabolome in Streptomyces kanasensis ZX01. Genes (Basel) 8: 346.

21. Ansari MZ, Yadav G, Gokhale RS, Mohanty D. 2004. NRPS-PKS: a knowledge-based resource for analysis of NRPS/PKS megasynthases. Nucleic Acids Res. 32: W405-413.

22. Kim MS, Cho WJ, Song MC, Park SW, Kim K, Kim E, et al. 2017. Engineered biosynthesis of milbemycins in the avermectin high-producing strain Streptomyces avermitilis. Microb. Cell Fact. 16: 9.

23. Ikeda H, Ishikawa J, Hanamoto A, Shinose M, Kikuchi $H$, Shiba $\mathrm{T}$, et al. 2003. Complete genome sequence and comparative analysis of the industrial microorganism Streptomyces avermitilis. Nat. Biotechnol. 21: 526-531.

24. Bode HB, Bethe B, Hofs R, Zeeck A. 2002. Big effects from small changes: possible ways to explore nature's chemical diversity. Chembiochem. 3: 619-627.

25. Marmann A, Aly AH, Lin W, Wang B, Proksch P. 2014. Co-cultivation--a powerful emerging tool for enhancing the 
chemical diversity of microorganisms. Mar. Drugs. 12: 1043-1065.

26. Baral B, Akhgari A, Metsa-Ketela M. 2018. Activation of microbial secondary metabolic pathways: Avenues and challenges. Synth. Syst. Biotechnol. 3: 163-178.

27. King AA, Chater KF. 1986. The expression of the Escherichia coli lacZ gene in Streptomyces. J. Gen. Microbiol. 132: 1739-1752.

28. Lussier FX, Denis F, Shareck F. 2010. Adaptation of the highly productive T7 expression system to Streptomyces lividans. Appl. Environ. Microbiol. 76: 967-970.

29. Mitra A, Angamuthu K, Jayashree HV, Nagaraja V. 2009. Occurrence, divergence and evolution of intrinsic terminators across eubacteria. Genomics 94: 110-116.

30. Bibb MJ, White J, Ward JM, Janssen GR. 1994. The mRNA for the $23 \mathrm{~S}$ rRNA methylase encoded by the ermE gene of Saccharopolyspora erythraea is translated in the absence of a conventional ribosome-binding site. Mol. Microbiol. 14: 533-545.

31. Bibb MJ, Janssen GR, Ward JM. 1985. Cloning and analysis of the promoter region of the erythromycin resistance gene (ermE) of Streptomyces erythraeus. Gene 38: 215-226.

32. Kieser T, Bibb M, Buttner M, Chater K, Hopwood D. 2000. Practical Streptomyces Genetics. John Innes Foundation, Norwich, England.

33. Wang W, Li X, Wang J, Xiang S, Feng X, Yang K. 2013. An engineered strong promoter for Streptomycetes. Appl. Environ. Microbiol. 79: 4484-4492.

34. Labes G, Bibb M, Wohlleben W. 1997. Isolation and characterization of a strong promoter element from the Streptomyces ghanaensis phage I19 using the gentamicin resistance gene (aacC1) of Tn 1696 as reporter. Microbiology 143: $1503-1512$

35. Shao Z, Rao G, Li C, Abil Z, Luo Y, Zhao H. 2013. Refactoring the silent spectinabilin gene cluster using a plug-and-play scaffold. ACS Synth. Biol. 2: 662-669.

36. Sohoni SV, Fazio A, Workman CT, Mijakovic I, Lantz AE. 2014. Synthetic promoter library for modulation of actinorhodin production in Streptomyces coelicolor A3(2). PLoS One 9: e99701.

37. Seghezzi N, Amar P, Koebmann B, Jensen PR, Virolle MJ. 2011. The construction of a library of synthetic promoters revealed some specific features of strong Streptomyces promoters. Appl. Microbiol. Biotechnol. 90: 615-623.

38. Luo Y, Zhang L, Barton KW, Zhao H. 2015. Systematic identification of a panel of strong constitutive promoters from Streptomyces albus. ACS Synth. Biol. 4: 1001-1010.

39. Li S, Wang J, Li X, Yin S, Wang W, Yang K. 2015. Genomewide identification and evaluation of constitutive promoters in Streptomycetes. Microb. Cell Fact. 14: 172.

40. Murakami T, Holt TG, Thompson CJ. 1989. Thiostreptoninduced gene expression in Streptomyces lividans. J. Bacteriol. 171: $1459-1466$

41. Takano E, White J, Thompson CJ, Bibb MJ. 1995. Construction of thiostrepton-inducible, high-copy-number expression vectors for use in Streptomyces spp. Gene 166: 133-137.

42. Huang H, Zheng G, Jiang W, Hu H, Lu Y. 2015. One-step high-efficiency CRISPR/Cas9-mediated genome editing in Streptomyces. Acta Biochim. Biophys. Sin (Shanghai) 47: 231-243.

43. Rodriguez-Garcia A, Combes P, Perez-Redondo R, Smith MC, Smith MC. 2005. Natural and synthetic tetracyclineinducible promoters for use in the antibiotic-producing bacteria Streptomyces. Nucleic Acids Res. 33: e87.

44. Horbal L, Fedorenko V, Luzhetskyy A. 2014. Novel and tightly regulated resorcinol and cumate-inducible expression systems for Streptomyces and other actinobacteria. Appl. Microbiol. Biotechnol. 98: 8641-8655.

45. Herai S, Hashimoto Y, Higashibata H, Maseda H, Ikeda H, Omura S, et al. 2004. Hyper-inducible expression system for Streptomycetes. Proc. Natl. Acad. Sci. USA 101: 14031-14035.

46. Noguchi Y, Kashiwagi N, Uzura A, Ogino C, Kondo A, Ikeda $\mathrm{H}$, et al. 2018. Development of a strictly regulated xylose-induced expression system in Streptomyces. Microb. Cell Fact. 17: 151.

47. Hindle Z, Smith CP. 1994. Substrate induction and catabolite repression of the Streptomyces coelicolor glycerol operon are mediated through the GylR protein. Mol. Microbiol. 12: 737-745.

48. Ward JM, Janssen GR, Kieser T, Bibb MJ, Buttner MJ, Bibb MJ. 1986. Construction and characterisation of a series of multicopy promoter-probe plasmid vectors for Streptomyces using the aminoglycoside phosphotransferase gene from Tn5 as indicator. Mol. Gen. Genet. 203: 468-478.

49. Pulido D, Jimenez A, Salas M, Mellado RP. 1987. A Bacillus subtilis phage phi 29 transcription terminator is efficiently recognized in Streptomyces lividans. Gene 56: 277-282.

50. Cobb RE, Wang Y, Zhao H. 2015. High-efficiency multiplex genome editing of Streptomyces species using an engineered CRISPR/Cas system. ACS Synth. Biol. 4: 723-728.

51. West S, Proudfoot NJ. 2009. Transcriptional termination enhances protein expression in human cells. Mol. Cell. 33: 354-364.

52. Mapendano CK, Lykke-Andersen S, Kjems J, Bertrand E, Jensen TH. 2010. Crosstalk between mRNA $3^{\prime}$ end processing and transcription initiation. Mol. Cell. 40: 410-422.

53. Dar D, Shamir M, Mellin JR, Koutero M, Stern-Ginossar N, Cossart P, et al. 2016. Term-seq reveals abundant riboregulation of antibiotics resistance in bacteria. Science 352: aad9822.

54. Lu P, Vogel C, Wang R, Yao X, Marcotte EM. 2007. Absolute protein expression profiling estimates the relative contributions of transcriptional and translational regulation. Nat. Biotechnol. 25: 117-124.

55. Jeong Y, Kim JN, Kim MW, Bucca G, Cho S, Yoon YJ, et al. 2016. The dynamic transcriptional and translational landscape of the model antibiotic producer Streptomyces coelicolor A3(2). Nat. Commun. 7: 11605. 
56. Makrides SC. 1996. Strategies for achieving high-level expression of genes in Escherichia coli. Microbiol. Rev. 60: 512-538.

57. Na D, Lee D. 2010. RBSDesigner: software for designing synthetic ribosome binding sites that yields a desired level of protein expression. Bioinformatics 26: 2633-2634.

58. Bai C, Zhang Y, Zhao X, Hu Y, Xiang S, Miao J, et al. 2015. Exploiting a precise design of universal synthetic modular regulatory elements to unlock the microbial natural products in Streptomyces. Proc. Natl. Acad. Sci. USA 112: 12181-12186.

59. Yi JS, Kim MW, Kim M, Jeong Y, Kim EJ, Cho BK, et al. 2017. A novel approach for gene expression optimization through native promoter and 5' UTR combinations based on RNA-seq, Ribo-seq, and TSS-seq of Streptomyces coelicolor. ACS Synth. Biol. 6: 555-565.

60. Janssen GR, Bibb MJ. 1990. Tandem promoters, tsrp1 and tsrp2, direct transcription of the thiostrepton resistance gene (tsr) of Streptomyces azureus: transcriptional initiation from tsrp2 occurs after deletion of the -35 region. Mol. Gen. Genet. 221: 339-346.

61. Sohaskey CD, Im H, Nelson AD, Schauer AT. 1992. Tn4556 and luciferase: synergistic tools for visualizing transcription in Streptomyces. Gene 115: 67-71.

62. Ingram C, Brawner M, Youngman P, Westpheling J. 1989. $x y l E$ functions as an efficient reporter gene in Streptomyces spp.: use for the study of galP1, a catabolite-controlled promoter. J. Bacteriol. 171: 6617-6624.

63. Myronovskyi M, Welle E, Fedorenko V, Luzhetskyy A. 2011. Beta-glucuronidase as a sensitive and versatile reporter in actinomycetes. Appl. Environ Microbiol. 77: 5370-5383.

64. Flores FJ, Rincon J, Martin JF. 2003. Characterization of the iron-regulated desA promoter of Streptomyces pilosus as a system for controlled gene expression in actinomycetes. Microb. Cell Fact. 2: 5.

65. Willemse J, van Wezel GP. 2009. Imaging of Streptomyces coelicolor A3(2) with reduced autofluorescence reveals a novel stage of FtsZ localization. PLoS One 4: e4242.

66. Santos-Beneit F, Errington J. 2017. Green fluorescent protein as a reporter for the spatial and temporal expression of actIII in Streptomyces coelicolor. Arch. Microbiol. 199: 875-880.

67. Nguyen KD, Au-Young SH, Nodwell JR. 2007. Monomeric red fluorescent protein as a reporter for macromolecular localization in Streptomyces coelicolor. Plasmid 58: 167-173.

68. Phelan RM, Sachs D, Petkiewicz SJ, Barajas JF, Blake-Hedges JM, Thompson MG, et al. 2017. Development of next generation synthetic biology tools for use in Streptomyces venezuelae. ACS Synth. Biol. 6: 159-166.

69. Siegl T, Luzhetskyy A. 2012. Actinomycetes genome engineering approaches. Antonie Van Leeuwenhoek. 102: 503516 .

70. Herrmann S, Siegl T, Luzhetska M, Petzke L, Jilg C, Welle E, et al. 2012. Site-specific recombination strategies for engineering actinomycete genomes. Appl. Environ. Microbiol. 78: 1804-1812.

71. Khodakaramian G, Lissenden S, Gust B, Moir L, Hoskisson PA, Chater KF, et al. 2006. Expression of Cre recombinase during transient phage infection permits efficient marker removal in Streptomyces. Nucleic Acids Res. 34: e20.

72. Zelyas N, Tahlan K, Jensen SE. 2009. Use of the native flp gene to generate in-frame unmarked mutations in Streptomyces spp. Gene 443: 48-54.

73. Barrangou R, Fremaux C, Deveau H, Richards M, Boyaval P, Moineau S, et al. 2007. CRISPR provides acquired resistance against viruses in prokaryotes. Science 315: 1709-1712.

74. Cong L, Ran FA, Cox D, Lin S, Barretto R, Habib N, et al. 2013. Multiplex genome engineering using CRISPR/Cas systems. Science 339: 819-823.

75. DiCarlo JE, Norville JE, Mali P, Rios X, Aach J, Church GM. 2013. Genome engineering in Saccharomyces cerevisiae using CRISPR-Cas systems. Nucleic Acids Res. 41: 4336-4343.

76. Friedland AE, Tzur YB, Esvelt KM, Colaiacovo MP, Church GM, Calarco JA. 2013. Heritable genome editing in C. elegans via a CRISPR-Cas9 system. Nat. Methods 10: 741743.

77. Jiang W, Bikard D, Cox D, Zhang F, Marraffini LA. 2013. RNA-guided editing of bacterial genomes using CRISPRCas systems. Nat. Biotechnol. 31: 233-239.

78. Li JF, Norville JE, Aach J, McCormack M, Zhang D, Bush J, et al. 2013. Multiplex and homologous recombinationmediated genome editing in Arabidopsis and Nicotiana benthamiana using guide RNA and Cas9. Nat. Biotechnol. 31: 688-691.

79. Jinek M, Chylinski K, Fonfara I, Hauer M, Doudna JA, Charpentier E. 2012. A programmable dual-RNA-guided DNA endonuclease in adaptive bacterial immunity. Science 337: 816-821.

80. Bibikova M, Beumer K, Trautman JK, Carroll D. 2003. Enhancing gene targeting with designed zinc finger nucleases. Science 300: 764.

81. Christian M, Cermak T, Doyle EL, Schmidt C, Zhang F, Hummel A, et al. 2010. Targeting DNA double-strand breaks with TAL effector nucleases. Genetics 186: 757-761.

82. Rouet P, Smih F, Jasin M. 1994. Introduction of doublestrand breaks into the genome of mouse cells by expression of a rare-cutting endonuclease. Mol. Cell Biol. 14: 8096-8106.

83. Doudna JA, Charpentier E. 2014. Genome editing. The new frontier of genome engineering with CRISPR-Cas9. Science 346: 1258096.

84. Anders C, Niewoehner O, Duerst A, Jinek M. 2014. Structural basis of PAM-dependent target DNA recognition by the Cas9 endonuclease. Nature 513: 569-573.

85. Mojica FJ, Diez-Villasenor C, Garcia-Martinez J, Almendros C. 2009. Short motif sequences determine the targets of the prokaryotic CRISPR defence system. Microbiology 155: 733740. 
86. Tong Y, Charusanti P, Zhang L, Weber T, Lee SY. 2015. CRISPR-Cas9 based engineering of actinomycetal genomes. ACS Synth. Biol. 4: 1020-1029.

87. Zhang MM, Wong FT, Wang Y, Luo S, Lim YH, Heng E, et al. 2017. CRISPR-Cas9 strategy for activation of silent Streptomyces biosynthetic gene clusters. Nat. Chem. Biol. 13: 607-609.

88. Zeng H, Wen S, Xu W, He Z, Zhai G, Liu Y, et al. 2015. Highly efficient editing of the actinorhodin polyketide chain length factor gene in Streptomyces coelicolor M145 using CRISPR/Cas9-CodA(sm) combined system. Appl. Microbiol. Biotechnol. 99: 10575-10585.

89. Li L, Zheng G, Chen J, Ge M, Jiang W, Lu Y. 2017. Multiplexed site-specific genome engineering for overproducing bioactive secondary metabolites in actinomycetes. Metab. Eng. 40: 80-92.

90. Meng J, Feng R, Zheng G, Ge M, Mast Y, Wohlleben W, et al. 2017. Improvement of pristinamycin I (PI) production in Streptomyces pristinaespiralis by metabolic engineering approaches. Synth. Syst. Biotechnol. 2: 130-136.

91. Qin Z, Munnoch JT, Devine R, Holmes NA, Seipke RF, Wilkinson KA, et al. 2017. Formicamycins, antibacterial polyketides produced by Streptomyces formicae isolated from African Tetraponera plant-ants. Chem. Sci. 8: 3218-3227.

92. Wang Y, Cobb RE, Zhao H. 2016. High-efficiency genome editing of Streptomyces species by an engineered CRISPR/ Cas System. Methods Enzymol. 575: 271-284.

93. Jia H, Zhang L, Wang T, Han J, Tang H, Zhang L. 2017. Development of a CRISPR/Cas9-mediated gene-editing tool in Streptomyces rimosus. Microbiology 163: 1148-1155.

94. Tao W, Yang A, Deng Z, Sun Y. 2018. CRISPR/Cas9-based editing of Streptomyces for discovery, characterization, and production of natural products. Front Microbiol. 9: 1660.

95. Liu Y, Tao W, Wen S, Li Z, Yang A, Deng Z, et al. 2015. In vitro CRISPR/Cas9 system for efficient targeted DNA editing. MBio 6: e01714-01715.

96. Jiang W, Zhao X, Gabrieli T, Lou C, Ebenstein Y, Zhu TF. 2015. Cas9-assisted targeting of chromosome segments $\mathrm{CATCH}$ enables one-step targeted cloning of large gene clusters. Nat. Commun. 6: 8101 .

97. Kang HS, Charlop-Powers Z, Brady SF. 2016. Multiplexed CRISPR/Cas9- and TAR-mediated promoter engineering of natural product biosynthetic gene clusters in yeast. ACS Synth. Biol. 5: 1002-1010.

98. Tao W, Yurkovich ME, Wen S, Lebe KE, Samborskyy M, Liu Y, et al. 2016. A genomics-led approach to deciphering the mechanism of thiotetronate antibiotic biosynthesis. Chem. Sci. 7: 376-385.

99. Li L, Wei K, Liu X, Wu Y, Zhensg G, Chen S, et al. 2019. aMSGE: advanced multiplex site-specific genome engineering with orthogonal modular recombinases in actinomycetes. Metab. Eng. 52: 153-167.
100. Qi LS, Larson MH, Gilbert LA, Doudna JA, Weissman JS, Arkin AP, et al. 2013. Repurposing CRISPR as an RNAguided platform for sequence-specific control of gene expression. Cell 152: 1173-1183.

101. Zhao Y, Li L, Zheng G, Jiang W, Deng Z, Wang Z, et al. 2018. CRISPR/dCas9-mediated multiplex gene repression in Streptomyces. Biotechnol. J. 13: e1800121.

102. Xu Z, Wang Y, Chater KF, Ou HY, Xu HH, Deng Z, et al. 2017. Large-scale transposition mutagenesis of Streptomyces coelicolor identifies hundreds of genes influencing antibiotic biosynthesis. Appl. Environ. Microbiol. 83: e02889-02816.

103. Komatsu M, Uchiyama T, Omura S, Cane DE, Ikeda H. 2010. Genome-minimized Streptomyces host for the heterologous expression of secondary metabolism. Proc. Natl. Acad. Sci. USA 107: 2646-2651.

104. Gomez-Escribano JP, Bibb MJ. 2011. Engineering Streptomyces coelicolor for heterologous expression of secondary metabolite gene clusters. Microb. Biotechnol. 4: 207-215.

105. Zetsche B, Gootenberg JS, Abudayyeh OO, Slaymaker IM, Makarova KS, Essletzbichler P, et al. 2015. Cpf1 is a single RNA-guided endonuclease of a class 2 CRISPR-Cas system. Cell 163: 759-771.

106. Li L, Wei K, Zheng G, Liu X, Chen S, Jiang W, et al. 2018. CRISPR-Cpf1-assisted multiplex genome editing and transcriptional repression in Streptomyces. Appl. Environ. Microbiol. 84: e00827-00818.

107. Xu M, Wright GD. 2018. Heterologous expression-facilitated natural products' discovery in actinomycetes. J. Ind. Microbiol. Biotechnol. 46: 415-431.

108. Liu R, Deng Z, Liu T. 2018. Streptomyces species: Ideal chassis for natural product discovery and overproduction. Metab. Eng. 50: 74-84.

109. Nah HJ, Pyeon HR, Kang SH, Choi SS, Kim ES. 2017. Cloning and heterologous expression of a large-sized natural product biosynthetic gene cluster in Streptomyces Species. Front. Microbiol. 8: 394.

110. Rutledge PJ, Challis GL. 2015. Discovery of microbial natural products by activation of silent biosynthetic gene clusters. Nat. Rev. Microbiol. 13: 509-523.

111. Katz M, Hover BM, Brady SF. 2016. Culture-independent discovery of natural products from soil metagenomes. $J$ Ind. Microbiol Biotechnol. 43: 129-141.

112. Pyeon HR, Nah HJ, Kang SH, Choi SS, Kim ES. 2017. Heterologous expression of pikromycin biosynthetic gene cluster using Streptomyces artificial chromosome system. Microb. Cell Fact. 16: 96.

113. Nah HJ, Woo MW, Choi SS, Kim ES. 2015. Precise cloning and tandem integration of large polyketide biosynthetic gene cluster using Streptomyces artificial chromosome system. Microb. Cell Fact. 14: 140.

114. Du D, Wang L, Tian Y, Liu H, Tan H, Niu G. 2015. Genome engineering and direct cloning of antibiotic gene 
clusters via phage varphiBT1 integrase-mediated sitespecific recombination in Streptomyces. Sci Rep. 5: 8740.

115. Greunke C, Duell ER, D'Agostino PM, Glockle A, Lamm K, Gulder TAM. 2018. Direct pathway cloning (DiPaC) to unlock natural product biosynthetic potential. Metab. Eng. 47: 334-345.

116. Shao Z, Luo Y, Zhao H. 2011. Rapid characterization and engineering of natural product biosynthetic pathways via DNA assembler. Mol. Biosyst. 7: 1056-1059.

117. Fu J, Bian X, Hu S, Wang H, Huang F, Seibert PM, et al. 2012. Full-length RecE enhances linear-linear homologous recombination and facilitates direct cloning for bioprospecting. Nat. Biotechnol. 30: 440-446.

118. Yamanaka K, Reynolds KA, Kersten RD, Ryan KS, Gonzalez DJ, Nizet V, et al. 2014. Direct cloning and refactoring of a silent lipopeptide biosynthetic gene cluster yields the antibiotic taromycin A. Proc. Natl. Acad. Sci. USA 111: 1957-1962.

119. Orr-Weaver TL, Szostak JW, Rothstein RJ. 1981. Yeast transformation: a model system for the study of recombination. Proc. Natl. Acad. Sci USA 78: 6354-6358.

120. Lee NC, Larionov V, Kouprina N. 2015. Highly efficient CRISPR/Cas9-mediated TAR cloning of genes and chromosomal loci from complex genomes in yeast. Nucleic Acids Res. 43: e55.

121. Bu QT, Yu P, Wang J, Li ZY, Chen XA, Mao XM, et al. 2019. Rational construction of genome-reduced and highefficient industrial Streptomyces chassis based on multiple comparative genomic approaches. Microb. Cell Fact. 18: 16.

122. Myronovskyi M, Rosenkranzer B, Nadmid S, Pujic P, Normand P, Luzhetskyy A. 2018. Generation of a clusterfree Streptomyces albus chassis strains for improved heterologous expression of secondary metabolite clusters. Metab. Eng. 49: 316-324.

123. Xu M, Wang $Y$, Zhao Z, Gao G, Huang SX, Kang Q, et al. 2016. Functional genome mining for metabolites encoded by large gene clusters through heterologous expression of a whole-genome bacterial artificial chromosome library in Streptomyces spp. Appl. Environ. Microbiol. 82: 5795-5805.

124. Liu Q, Xiao L, Zhou Y, Deng K, Tan G, Han Y, et al. 2016. Development of Streptomyces sp. FR-008 as an emerging chassis. Synth. Syst. Biotechnol. 1: 207-214.

125. Komatsu M, Komatsu K, Koiwai H, Yamada Y, Kozone I, Izumikawa M, et al. 2013. Engineered Streptomyces avermitilis host for heterologous expression of biosynthetic gene cluster for secondary metabolites. ACS Synth. Biol. 2: 384-396.

126. Daniels W, Bouvin J, Busche T, Kalinowski J, Bernaerts K. 2016. Finding targets for genome reduction in Streptomyces lividans TK24 using flux balance analysis. IFAC-PapersOnLine 49: 252-257.

127. Toro L, Pinilla L, Avignone-Rossa C, Rios-Estepa R. 2018. An enhanced genome-scale metabolic reconstruction of
Streptomyces clavuligerus identifies novel strain improvement strategies. Bioprocess Biosyst. Eng. 41: 657-669.

128. Kallifidas D, Jiang G, Ding Y, Luesch H. 2018. Rational engineering of Streptomyces albus J1074 for the overexpression of secondary metabolite gene clusters. Microb. Cell Fact. 17: 25.

129. Machado H, Tuttle RN, Jensen PR. 2017. Omics-based natural product discovery and the lexicon of genome mining. Curr. Opin. Microbiol. 39: 136-142.

130. Ran FA, Cong L, Yan WX, Scott DA, Gootenberg JS, Kriz AJ, et al. 2015. In vivo genome editing using Staphylococcus aureus Cas9. Nature 520: 186-191.

131. Liu JJ, Orlova N, Oakes BL, Ma E, Spinner HB, Baney KLM, et al. 2019. CasX enzymes comprise a distinct family of RNA-guided genome editors. Nature 566: 218-223.

132. Bikard D, Jiang W, Samai P, Hochschild A, Zhang F, Marraffini LA. 2013. Programmable repression and activation of bacterial gene expression using an engineered CRISPRCas system. Nucleic Acids Res. 41: 7429-7437.

133. Siu KH, Chen W. 2019. Riboregulated toehold-gated gRNA for programmable CRISPR-Cas9 function. Nat. Chem. Biol. 15: $217-220$.

134. Bunet R, Song L, Mendes MV, Corre C, Hotel L, Rouhier N, et al. 2011. Characterization and manipulation of the pathway-specific late regulator AlpW reveals Streptomyces ambofaciens as a new producer of Kinamycins. J. Bacteriol. 193: $1142-1153$.

135. Miao V, Coeffet-Legal MF, Brian P, Brost R, Penn J, Whiting A, et al. 2005. Daptomycin biosynthesis in Streptomyces roseosporus: cloning and analysis of the gene cluster and revision of peptide stereochemistry. Microbiology 151: 15071523.

136. Myronovskyi M, Rosenkranzer B, Luzhetskyy A. 2014. Iterative marker excision system. Appl. Microbiol. Biotechnol. 98: 4557-4570.

137. Thapa LP, Oh TJ, Lee HC, Liou K, Park JW, Yoon YJ, et al. 2007. Heterologous expression of the kanamycin biosynthetic gene cluster (pSKC2) in Streptomyces venezuelae YJ003. Appl. Microbiol. Biotechnol. 76: 1357-1364.

138. Jones AC, Gust B, Kulik A, Heide L, Buttner MJ, Bibb MJ. 2013. Phage p1-derived artificial chromosomes facilitate heterologous expression of the FK506 gene cluster. PLoS One 8: e69319.

139. Steffensky M, Muhlenweg A, Wang ZX, Li SM, Heide L. 2000. Identification of the novobiocin biosynthetic gene cluster of Streptomyces spheroides NCIB 11891. Antimicrob. Agents Chemother. 44: 1214-1222.

140. Zhao Z, Shi T, Xu M, Brock NL, Zhao YL, Wang Y, et al. 2016. Hybrubins: Bipyrrole tetramic acids obtained by crosstalk between a truncated undecylprodigiosin pathway and heterologous tetramic acid biosynthetic genes. Org. Lett. 18: 572-575. 